Manuscript proposal - Review - for the Special Issue of Biochimica et Biophysica Acta Journal - Proteins and Proteomics entitled "D-amino acids: biology in the mirror", featuring highlights of the IDAR2017 meeting.

5

\title{
D-Amino Acids in Molecular Evolution in Space - Absolute Asymmetric Photolysis and Synthesis of Amino Acids by Circularly Polarized Light
}

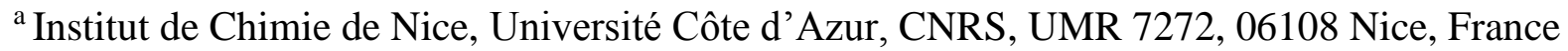

${ }^{\mathrm{b}}$ L'Orme des Merisiers, Synchrotron SOLEIL, BP 48 Saint Aubin, 91192 Gif-sur-Yvette, France

${ }^{\mathrm{c}}$ ISA, Department of Physics and Astronomy, Aarhus University, 8000 Aarhus C, Denmark

${ }^{\mathrm{d}}$ Graduate School of Pharmaceutical Sciences, Kyushu University, Fukuoka, Japan

${ }^{\mathrm{e}}$ Department of Biogeochemistry, Japan Agency for Marine-Earth Science and Technology

(JAMSTEC), 2-15 Natsushima, Yokosuka, Kanagawa, 237-0061, Japan

Living organisms on the Earth almost exclusively use L-amino acids for the molecular architecture of proteins. The biological occurrence of D-amino acids is rare, although their functions in various organisms are being gradually understood. A possible explanation for the origin of biomolecular homochirality is the delivery of enantioenriched molecules via extraterrestrial bodies, such as asteroids and comets on early Earth. For the asymmetric formation of amino acids and their precursor molecules in interstellar environments, the interaction with circularly polarized photons is considered to have played a potential role in causing chiral asymmetry. In this review, we summarize recent progress in the investigation of chirality transfer from chiral photons to amino acids involving the two major processes of asymmetric photolysis and asymmetric synthesis. We will discuss analytical data on cometary and meteoritic amino acids and their potential impact delivery to the early Earth. The ongoing and future ambitious space missions, Hayabusa2, OSIRIS-REx, ExoMars 2020, and MMX, are scheduled to provide new insights into the chirality of extraterrestrial organic molecules and their potential relation to the terrestrial homochirality.

Key words: Homochirality, Asymmetric Photolysis, Asymmetric Synthesis, Circularly 
Abbreviations: Ala, alanine; Glu, glutamic acid; Met, methionine; Leu, leucine; Tyr, tyrosine; Phe, phenylalanine; Asp, aspartic acid; Ser, serine; Arg, arginine; His, histidine; Pro, proline; Asn, asparagine; NVal, norvaline; NLeu, norleucine; Ile, isoleucine; ABA, aminobutyric acid; iVal, isovaline, $\alpha$-methyl-Val, $\alpha$-methylvaline; Trp, tryptophan; Cys, cysteine; $\beta$-Ala, $\beta$-alanine; AIB, aminoisobutyric acid; Sar, sarcosine; HMT, hexamethylenetetramine; 2,3-DAP, 2,3-diaminopropanoic acid; EACA, $\varepsilon$-amino- $n$-caproic acid; allo-Ile, alloisoleucine, 2-a-2,3-DMPA, 2-amino-2,3-dimethylpentanoic acid; ee, enantiomeric excess; ISM, interstellar medium; CPL, circularly polarized light; R-CPL, righthanded circularly polarized light; L-CPL, left-handed circularly polarized light; $e e_{\mathrm{L}}, \mathrm{L}-$ enantiomeric excess, UV, ultraviolet; VUV, Vacuum Ultra-Violet; NIR, near infrared; CP, circular polarization; VUV, vacuum ultraviolet; $\mathrm{CD}$, circular dichroism; ORD, optical rotatory dispersion; $\mathrm{PEM}$, photoelastic modulator; $\mathrm{GC} \times \mathrm{GC}-\mathrm{TOFMS}$, multidimensional gas chromatography coupled to time-of-flight mass spectrometry; ISM/CSM, interstellar/circumstellar medium; HOMO, highest occupied molecular orbital; 2D-HPLC, two-dimensional chiral high-performance liquid chromatography; GC/MS, Gas Chromatography/Mass Spectrometry; ADS, Active Descent System; SD², Sample Drilling and Distribution; COSAC, Cometary Sampling and Composition; ROSINA, Rosetta Orbiter Spectrometer for Ion and Neutral Analysis; IDPs, interplanetary dust particles; OSIRIS-REx, Origins, Spectral Interpretation, Resource Identification, Security, Regolith Explorer; MMX, Martian Moons eXploration; C-type, carbonaceous-type; MOMA, Mars Organic Molecule Analyzer; LDMS, Laser Desorption Mass Spectrometry; NBD-F, 4-fluoro-7-nitro-2,1,3benzoxadiazole; MTBSTFA, $N, N$-methyl-test-butyl-dimethylsilyltrifluoroacetamide; DMFDMA, $N, N$-Dimethylformamide dimethyl acetal; MSL, Mars Science Laboratory; ESA, European Space Agency; JAXA, Japan Aerospace Exploration Agency; NASA, National Aeronautics and Space Administration. 


\section{Introduction}

\subsection{The Emergence of Biomolecular Homochirality}

Homochirality is an essential molecular characteristic of terrestrial life. Living organisms on Earth almost exclusively use only one enantiomer for the molecular architecture of their biopolymers: L-amino acids (left-handed) for proteins and D-sugars (right-handed) for nucleic acids. There are no differences between D- and L-enantiomers with regard to chemical and physical properties in an achiral environment, except for tiny energy differences between enantiomers due to parity violation in the weak interaction [1]. Although there are a number of works that have attempted to connect parity violation with the origin of biomolecular homochirality, a clear relationship has not yet been revealed [e.g., 2-5]. The selection of one enantiomer is an important requirement when building up biopolymers such as proteins. The existence of a variety of diastereoisomers would interfere with the proper folding of proteins. Thus, the selection of enantiomers with only a single handedness must have occurred at an early stage during the evolution of life. However, the preference of L-amino acids, as well as D-sugars, over the optical antipodes is a longstanding question hitherto unanswered.

\subsection{D-Amino Acids in Organisms}

The investigation of the existence of enantiomers in the form of D-amino acids in living organisms is an increasingly developing and fascinating research field. It has been known for some time that bacteria use D-amino acids in their cell walls, especially D- $\alpha$ alanine (D- $\alpha$-Ala) and D-glutamic acid (D-Glu), which are characteristic components of the peptide moiety of the peptidoglycan polymer [e.g., 6]. Peptidoglycan is a major constituent of the cell wall of gram-positive bacteria and to a lesser extent gram-negative bacteria [6]. Recent advances in analytical chemistry have enabled the chiral separation, identification, and quantification of minor D-amino acids and thereby many more 'unusual' D-amino acids have been discovered [e.g., 7]. It has become apparent that bacteria produce various D-amino acids, such as D-methionine (D-Met), D-leucine (D-Leu), D-tyrosine (D-Tyr), and D-phenylalanine (D$\mathrm{Phe}$ ), to regulate the synthesis of peptidoglycan due to the changes in environmental conditions [8].

The discovery of D-amino acids has also expanded to include animals [e.g., 9, 10], in particular, D-aspartic acid (D-Asp) which is the most widely distributed amino acid in various animal phyla [10]. It is commonly found in the nervous and endocrine systems $[10,11]$ of octopuses and squids [12, 13], lobsters [14], marine molluscs [e.g., 15], fish [16], frogs [17], lizards [18], and birds [19]. D-Asp has been also identified in mammals, such as rats, mice, and even humans [e.g., 20, 21]. Another well-known D-amino acid in cellular life is D-serine (D-Ser). It widely exists in various classes of organisms and especially accumulates in brains of mammals in high concentration [22], where it plays a key role in the central nervous system as a neuromodulator [22]. Several other D-amino acids have also been identified in various species (e.g., D-Glu, D-arginine (D-Arg), D-Phe, D-Met, and D-histidine (D-His)). It is noteworthy that $\mathrm{D}-\alpha$-Ala is the predominant $\mathrm{D}$-amino acid in some aquatic invertebrates, such as marine crustaceans [23-25] and several species of bivalves [26]. The percentage of D- $\alpha$ Ala compared to the total $\alpha$-Ala abundance in some crustacean species ranges from 30 to up

110 to $60 \%[14,24]$ and was found to be involved in the osmoregulation against salinity changes [23].

The physiological functions and the origins of D-amino acids in mammals have been extensively investigated in recent years. D-Asp in endocrine and neuroendocrine tissues [e.g., 21] and D-Ser in brains [e.g., 27, 28] are the most studied. Several other D-amino acid

115 residues that have been discovered due to recent analytical developments [e.g., 29-31] include D-Glu, D-Ala, and D-Pro. D-Glu was recently found to be accumulated in heart tissue [32]. It has been recognized that D-amino acids could be used as biomarkers for aging and 
various diseases such as D-Ser for Alzheimer's disease [33] and chronic kidney disease [34], although the mechanisms are not fully revealed yet [e.g., 33-36]. In this case, D-amino acids are the result of racemization of proteinogenic amino acids, D-Asp, for example, has been detected in various tissues of elderly individuals due to the susceptibility of Asp to racemization [35].

The existence of D-amino acids in almost all living organisms raises a question about their origin. D-amino acids have most likely been incorporated into the organisms at several different stages in evolutional history and have developed specific physiological roles. The fact that the fundamental structure of terrestrial life is almost all of the same 'hand' could indicate that the selection of L-amino acids finished during an early stage in the emergence of life on early Earth.

\subsection{Origin of Homochirality}

When, how, and why L-amino acids were selected for terrestrial life are important and far-reaching questions in origins of life research. Many researchers have proposed physicochemical pathways for the symmetry breaking of chiral biomolecules. For example, Soai et al. demonstrated that chiral quartz promotes enantioselective synthesis of organic molecules and subsequent enhancement of the enantiomeric excess (ee) by autocatalytic reactions and yielded significantly high ee (93-97\%)[37]. Hazen et al. and Orme et al. successfully used calcite as a mineral surface for enantioselective adsorption of amino acids $[38,39]$. Viedma reported on a unique phenomenon to obtain homochiral crystal aggregates from a racemic mixture known as "Viedma ripening" [40]. In his first experiment, he used a

140 saturated aqueous solution of racemic sodium chlorate $\left(\mathrm{NaClO}_{3}\right)$, which was prepared by dissolving an equal mixture of $d$ - and $l$-crystals with an excess of undissolved crystals, and employed mechanical abrasion-grinding by stirring with glass balls under isothermal conditions [40]. As a result, single-chiral crystals of complete chiral purity were formed. In spite of the practical simplicity, the underlying mechanism of Viedma ripening is quite complex and has not yet been fully understood. Enantiomer-specific oriented attachment is currently considered to be one of the key mechanisms [41]. In addition, there are strict requirements for Viedma ripening to be able to proceed, conglomerate crystallization, and racemization in solution [42], and thus only two amino acids (Asp and Glu) have been successfully subjected to Viedma ripening [43, 44].

150 The enantiomeric enrichment of naturally occurring L-amino acids [e.g., 45, 46] and D-sugar derivatives [47] found in carbonaceous meteorites has raised the hypothesis of a possible link between astrochemical evolution and the origin of biomolecular homochirality. Over the past decades, significant progress in the understanding of the formation of such complex molecules in the interstellar medium (ISM) and their incorporation into comets and other celestial bodies such as the parent bodies of primitive carbonaceous chondrites have been made. More than 160 different molecular species have been identified in the ISM by astronomical observations [e.g., 48-50]. Recently, the first chiral molecule, propylene oxide $\left(\mathrm{CH}_{3} \mathrm{CHCH}_{2} \mathrm{O}\right)$, was detected in the ISM [51], although with a non-enantio-selective detection scheme. Laboratory experiments simulating interstellar ice chemistries further

160 suggest the existence of even more complex organic molecules [e.g., 52-54], such as amino acids, which will be discussed in Chapter 3. Recent analytical improvements also revealed the synthesis of sugar and sugar related molecules in interstellar ice analogues [55, 56]. These interstellar organic molecules are considered to be inherited by comets. Approximately 30 different molecular species including radicals and ions have been detected by astronomical

165 observations [e.g., 57, 58]. Moreover, complex molecules, such as ethanol $\left(\mathrm{CH}_{3} \mathrm{CH}_{2} \mathrm{OH}\right)$ and the simplest sugar glycolaldehyde $\left(\mathrm{CH}_{2} \mathrm{OHCHO}\right)$, have been found in comet $\mathrm{C} / 2014 \mathrm{Q} 2$ (Lovejoy) [59]. 
The discovery of chiral organic molecules, including amino acids in carbonaceous chondrites, is still a controversial issue due to analytical difficulties and potential terrestrial contaminations. Chapter 4 will briefly highlight the analytical history and recent progress of amino acid detection in meteorite samples.

How amino acids can be asymmetrically formed in extraterrestrial environments will be the focus of Chapters 2 and 3. Circularly polarized light (CPL) is considered as a plausible candidate to cause chiral asymmetry in organic biomolecules. We will therefore discuss the two main photochemical processes by CPL, asymmetric photolysis (Chapter 2) and asymmetric synthesis (Chapter 3). We will further summarize the effects of impact shock on the chirality of amino acids after their delivery to early Earth by asteroids and comets in Chapter 5. Finally, several perspectives on the ongoing space missions aiming for a samplereturn from asteroids (Hayabusa2, Origins, Spectral Interpretation, Resource Identification, Security, Regolith Explorer (OSIRIS-REx), and Martian Moons eXploration (MMX) missions) and in situ analysis on Mars (ExoMars mission) will be provided in Chapter 6 with regard to the importance of pristine samples.

\section{Absolute Asymmetric Photolysis of Racemic Amino Acids 2.1. Driving Force for Symmetry Breaking in the Universe: Circularly Polarized Light (CPL)}

CPL represents an electromagnetic wave, whose electric field vector traces a spiral along with the direction of propagation (Figure 1). CPL exhibits true chirality and has the capability to induce chiral asymmetry into racemic organic molecules [60]. Thus, astronomical sources of CPL have been searched for in order to explain the detected Lenantiomeric excess $\left(e e_{\mathrm{L}}\right)$ values of meteoritic amino acids. Synchrotron radiation from neutron stars, the remnants of supernova explosions, were first suggested as the possible source of CPL [61, 62], but they turned out to be insignificant at visible and ultraviolet (UV) wavelengths [63]. Three other sources have been suggested to produce high degrees of circularly polarization and include: 1 ) high field magnetic white dwarfs, 2) Polars (magnetic white dwarf binaries), and 3) reflection nebulae in star-forming regions [63]. However, the chance of encountering single magnetic white dwarfs or Polars in molecular clouds is extremely low, and therefore represent very unlikely scenarios [63]. The most plausible source of CPL is found in star-forming regions, these represent an ideal place for the exposure of organic molecules to CPL in molecular clouds and in the outer part of protostellar discs of a newly forming solar system.

The Orion nebula is the nearest star-forming region where both high-mass and lowmass stars are being formed and has been extensively investigated in the search for CPL.

205 Bailey et al. discovered high levels of CPL of up to $+17 \%$ in the near infrared (NIR) in the high mass star-forming regions of Orion OMC-1 [64]. The circular polarization (CP) image of the Orion nebula showed a quadrupolar distribution of R- and L-CPL and the CP area extends far larger than the size of a typical protostellar disc. Fukue et al. showed the asymmetric quadrupolar pattern of $\mathrm{CP}(+17 \%$ to $-5 \%)$ in the massive star-forming region of the Orion

$210 \mathrm{BN} / \mathrm{KL}$ region, which is centered around the young star IRc2 [65]. This finding indicates that this massive young star IRc2 is the dominant source of the large CP [65]. The spatial distribution of the $\mathrm{CP}$ in this region extends to $\sim 0.4 \mathrm{pc}$, which is $\sim 400$ times larger than the size of our solar system [66]. Extensive observation of CP in other star-forming regions, especially the massive star-forming region NGC 6334-V revealed the existence of even higher 215 CP than in the Orion nebula (22\%), and at $0.65 \mathrm{pc}$ is even larger [67]. One of the mechanisms proposed to explain the observed CP in the star-forming regions is scattering from grains aligned by a magnetic field [e.g., 68]. Meanwhile, Kwon et al. argue that dichroic extinction 
of linearly polarized scattered light should be the main mechanism to produce the observed higher CP (>20\%) [67].

220 CPL has only been observed in the NIR wavelength region. The higher energies required for asymmetric photochemical reactions of organic molecules, such as vacuum UV (VUV)/UV photons, are not directly observable due to the high dust obscuration in the massive star-forming regions. However, calculations by Bailey et al. showed that substantial degrees of UV-CPL could be produced by the scattered light from aligned grains, based on

225 the observational results in the NIR [64]. All of the observed star-forming regions that have high $\mathrm{CP}$ are associated with massive stars. According to the evidence of short-lived

radionuclides in meteorites (e.g., ${ }^{60} \mathrm{Fe}$ ), which originate from a supernova explosion [e.g., 69, 70], our solar system is considered to have been formed in a massive star-forming region. Assuming that the size of our solar systems is about $200 \mathrm{AU}=0.001 \mathrm{pc}$, the observed size of $230 \quad 0.65 \mathrm{pc}$ of CP in NGC 6334-V is extremely large. Thus, it is possible to presume that our Solar System formed in a region where it was exposed to UV-CPL of one handedness only and this triggered the formation of L-enriched amino acids .

\subsection{Theoretical Background for Absolute Asymmetric Photolysis by CPL}

235 Photochemical reactions induced by CPL are often referred to as absolute asymmetric and distinguished from photochemical reactions of chiral molecules induced by non-polarized light [e.g., 71]. For CPL-induced asymmetric photochemical reactions, the following requirements need to be met: 1) the irradiated light must be absorbed by the reactants (Grotthus-Draper law), 2) the circular dichroism (CD) of the reactants at the irradiation 240 wavelength should not be zero, 3) the reactants must undergo irreversible photochemical transformation, 4) the interconversion of each enantiomer of the reactants should not occur thermally or photochemically, and 5) products should preferably be transparent at the irradiation wavelength $[72,73]$.

The study of the CD of chiral molecules allows for the understanding of their

245 interaction with CPL. CD measures the difference of the molar absorption coefficients (or extinction coefficients) between R- and L-CPL by enantiopure molecules and is expressed as following [e.g., 71]:

$$
\Delta \varepsilon=\varepsilon_{\mathrm{L}}-\varepsilon_{\mathrm{R}}
$$

The measurement of the differential absorption is wavelength dependent and recorded by CD spectroscopy. The reaction rates of each enantiomer irradiated by either L- or R-CPL are different. As a consequence, the chirality of CPL can be transferred into chiral or achiral molecules in favour of one enantiomer $[71,73]$.

Another chiroptical feature of chiral molecules is optical rotatory dispersion (ORD), which is the variation in the optical rotation of a molecule depending on the wavelength of

255 light. ORD is closely related to $\mathrm{CD}$. In the vicinity of a wavelength where CD shows a maximum peak, ORD changes from a maximum or minimum value to the opposite sign with equal magnitude by crossing zero. This phenomenon is known as the Cotton effect.

The first CD spectra of amino acids were recorded in the visible to the UV region only [e.g., 74], due to the limited photon intensity below $200 \mathrm{~nm}$ of commercial CD

260 photospectrometers [75]. The use of intense and highly collimated synchrotron radiation has enabled CD measurements in the VUV region $(\lambda<200 \mathrm{~nm})$, where amino acids exhibit intense absorption bands [76-78]. At most synchrotron radiation facilities, the polarization of the light beam is converted to R- and L-CPL using a photoelastic modulator (PEM) [75]. Recently, the use of an Onuki-type crossed undulator has further extended the accessible CD

265 range from 140 to $120 \mathrm{~nm}[79,80]$ and even to the soft $\mathrm{x}$-ray region by utilizing a sophisticated helicity switching system [81, 82]. 
The CD spectra of several $\alpha-\mathrm{H}$ amino acids ( $\alpha$-Ala, Val, norvaline (NVal), Leu, norleucine (NLeu), isoleucine (Ile), Ser, $\alpha$-aminobutyric acid ( $\alpha$-ABA), Pro, Phe) and $\alpha$ methyl amino acids (isovaline (iVal), $\alpha$-methylvaline ( $\alpha$-methyl-Val)), which are commonly found in meteorites (Figure 2a), have been successfully recorded [76-78]. To overcome the water absorption below $190 \mathrm{~nm}$, the CD spectra were measured in the solid amorphous state, usually by sublimating individual amino acid enantiomers on a $\mathrm{MgF}_{2}$ window [75]. The $\mathrm{CD}$ spectra of all measured $\alpha-\mathrm{H}$ amino acids showed characteristic CD bands between 140 and $190 \mathrm{~nm}$ and each pair of enantiomers show opposite signs with equal magnitudes [76, 77].

275 Some features were commonly observed among all $\alpha-\mathrm{H}$ amino acids, for example, the distinct CD peak between 165 and $185 \mathrm{~nm}$ was assigned to $\pi \rightarrow \pi^{*}$ transitions in the carboxyl group by theoretical calculations $[76,77]$. On the other hand, amino acids with a branched alkyl group in the side chain (Val, Leu, Ile) displayed a specific peak between 170 and $175 \mathrm{~nm}$ that is absent in straight-chain amino acids [77]. Furthermore, $\alpha$-methyl amino acids (iVal and $\alpha$ methyl-Val) showed an opposite CD sign compared to $\alpha-\mathrm{H}$ amino acids [76]. This could be related to the strong steric hindrance of $\alpha$-methyl amino acids at the stereogenic center, which may affect the molecular orbitals involved in the CD transition. It is noteworthy that the solid state CD spectra of amino acids clearly differ from their solution spectra [77, 83], especially at around $200 \mathrm{~nm}$. This can be explained by the conformational change between the solid and the liquid state e.g., change in the dihedral angles of the $\mathrm{COO}^{-}$and $\mathrm{NH}_{3}{ }^{+}$groups [77].

Although CD serves as a helpful measure for understanding the crucial wavelengthdependence of asymmetric photochemistry, another quantitative factor is necessary for the evaluation of the chirality transfer from chiral photons to racemic molecules. Kuhn combined the $\mathrm{CD}$ with the magnitude of absorption and introduced the anisotropy factor $g$, which is

290 defined as following [84]:

$$
g=\frac{\varepsilon_{l}-\varepsilon_{r}}{\varepsilon}=\frac{\Delta \varepsilon}{\varepsilon}=\frac{\Delta \varepsilon}{\left(\varepsilon_{r}+\varepsilon_{l}\right) / 2}
$$

The anisotropy factor $g$ is a wavelength-dependent and dimensionless quantity that ranges from 0 to 2 . In the case of asymmetric photolysis of racemic mixtures, the anisotropy factor $g$ can be represented by two competitive pseudo-first order reactions with unequal rate constants, $k_{\mathrm{S}}$ and $k_{\mathrm{R}}$, for the $R$ and $S$ enantiomers, respectively [84, 85]:

(4)

$$
g=2 \frac{\varepsilon_{R}-\varepsilon_{S}}{\varepsilon_{R}+\varepsilon_{S}}=2 \frac{k_{R}-k_{S}}{k_{R}+k_{S}}
$$

The rate constants of the two enantiomers are proportional to the molar absorption coefficients $\left(\varepsilon_{\mathrm{R}}\right.$ and $\left.\varepsilon_{\mathrm{S}}\right)$. This equation is also applicable to non-first-order kinetics [86]. The anisotropy factor $g$ further gives the quantitative prediction of the inducible $e e$ value by asymmetric photolysis [85]:

$$
e e \geq\left(1-(1-\xi)^{\frac{g}{2}}\right) \times 100 \%
$$

305 In this approximation, $e e$ is dependent on the anisotropy factor $g$ and the extent of the reaction $\xi$.

The anisotropy spectra of several amorphous solid state amino acids have been recorded between 130 and $350 \mathrm{~nm}$ using synchrotron radiation (Figure 2b) [83, 85]. The Lenantiomers of $\alpha-\mathrm{H}$ amino acids ( $\alpha$-Ala, Val, Leu, Ser, Pro) displayed a minimum between

$310 \quad 190-210 \mathrm{~nm}$ and a rather small maximum between 170-190 $\mathrm{nm}$ [85]. The peak at 190-210 $\mathrm{nm}$ is assigned to a $n \rightarrow \pi^{*}$ transition in the carboxylate anion mixed with the $n\left(\mathrm{COO}^{-}\right) \rightarrow$ $\sigma^{*}(\mathrm{~N}-\mathrm{H})$ transition and the peak at $170-190 \mathrm{~nm}$ can be assigned to the first $\pi \rightarrow \pi^{*}$ transition of the carboxylate anion $[78,85]$. On the contrary, the L-enantiomers of $\alpha$-methyl amino acids 
(iVal and $\alpha$-methyl-Val) did not show any prominent peaks, but a negative plateau between 200 and $220 \mathrm{~nm}$ [85]. The quantitative prediction of the inducible ee by CPL irradiation at $200 \mathrm{~nm}$ using equation (5) results in an $e e$ of 5\% (Leu) when $99.99 \%$ are photolyzed [85].

\subsection{Laboratory Experiments of Absolute Asymmetric Photolysis of Racemic Amino Acids}

The first asymmetric photolysis experiment of organic molecules using CPL was conducted by Kuhn \& Braun by irradiating a racemic solution of $\alpha$-bromopropanoic acid ethyl ester and examining the induced enantioenrichment [87]. After this pioneering work, several other molecules have been investigated [e.g., 88, 89], including amino acids [e.g., 90-92]. The asymmetric photolysis of amino acids was first tested in aqueous solution above $190 \mathrm{~nm}$.

325 Flores et al. irradiated racemic ( $\mathrm{rac}$ )-Leu, which was dissolved in $0.1 \mathrm{M} \mathrm{HCl}$, individually with R- and L-CPL at $212.8 \mathrm{~nm}$, and obtained $+1.98 \%$ ee for R-CPL and $-2.5 \%$ ee for L-CPL after a decomposition of $59 \%$ and $75 \%$, respectively [92]. Nishino et al. later focused on the $\mathrm{pH}$ dependence of the anisotropy factor $g$ and the inducible $e e$ into amino acids [93]. They showed that the intensity of the $g$ factor of aqueous D- and L-Leu increased with the decrease of the $\mathrm{pH}$ value of the solution, particularly in the wavelength range of $215-220 \mathrm{~nm}$. The highest $e e$ obtained in this study was $+1.3 \%$ at $\mathrm{pH} 1$ for a decomposition rate of $55 \%$. The authors argued that the preference of a lower $\mathrm{pH}$ for the high $g$ value was due to the $n \rightarrow \pi^{*}$ transition of the carboxyl group of Leu. The mechanism of the asymmetric photolysis of Leu was revealed as follows: CPL induced the enantioselective excitation of the carboxyl group of

335 Leu (D-enantiomer by R-CPL, and vice versa). For this excitation, a hydrogen atom from the $\gamma$-position was abstracted in a Norrish Type II reaction [94]. This abstraction lead to the cleavage of the $\mathrm{C}_{2}-\mathrm{C}_{3}$ bond and Gly was formed by the decomposition. This mechanism was predicted to be identical to other aliphatic amino acids that possess a $\gamma$-hydrogen (e.g., Val and Ile) [93]. In the subsequent report, the authors conducted a comprehensive study for all 20

340 proteinogenic amino acids, investigating the $\mathrm{pH}$ dependence of the $\mathrm{CD}$ and the anisotropy factor $g$ in the 190-260 nm wavelength domain [95]. Among the 20 amino acids, aliphatic amino acids ( $\alpha$-Ala, Leu, Val, Ile, Pro) and those that have hydroxyl groups (Ser, Thr) showed the highest $g$ values of $0.025-0.035$ at $216-226 \mathrm{~nm}$ and at $\mathrm{pH} \mathrm{1,} \mathrm{which} \mathrm{was} \mathrm{caused} \mathrm{by} \mathrm{the}$ carboxylic $n \rightarrow \pi^{*}$ transition. Amino acids that have aromatic constituents (Phe, Try, His,

345 tryptophan (Trp)) and sulfur (cysteine (Cys), Met) showed lower maximum $g$ values of $0.0007-0.014$ at $226-241 \mathrm{~nm}$. The former could be explained by the major contribution of the aromatic $\pi \rightarrow \pi^{*}$ transition and the latter due to the contribution of $n \rightarrow \sigma^{*}$ transition of the thiol group (Cys) and the sulfide group (Met).

The use of solid thin films of amino acids in combination with synchrotron radiation

350 allowed for asymmetric photochemical investigations in the VUV region $(<200 \mathrm{~nm})$.

Meierhenrich et al. succeeded in performing asymmetric photolysis of $r a c$-Leu in the solid state at 182 and $170 \mathrm{~nm}$ [96]. The irradiation of solid rac-Leu films with L-CPL at $182 \mathrm{~nm}$ resulted in the production of $+2.6 \% \mathrm{ee}$, while the irradiation at $170 \mathrm{~nm}$ induced only a minor $e e$ value. These results were consistent with the recorded CD spectra, in which the wavelength

$355183 \mathrm{~nm}$ matches with the positive $\pi^{*} \rightarrow \pi_{1}$ electronic transitions, while at $170 \mathrm{~nm}$ almost no $\mathrm{CD}$ contribution is observed. In subsequent experiments, the authors showed even higher $e e$ values of $+5.2 \%( \pm 0.5 \%)$ by the irradiation of $r a c$-Leu films with R-CPL at $187 \mathrm{~nm}$ at a total photolysis rate of $99.23 \%$ [97]. Although there was no counterpart experiment with the opposite-handed CPL irradiation [96, 97], Meinert et al. confirmed the experiments using a rac-Ala film (Figure 3). In the experiments, they prepared an amorphous rac-Ala film, which was labelled with ${ }^{13} \mathrm{C}$ to avoid any biological contamination, and applied an improved analytical technique by using multidimensional gas chromatography coupled to time-of-flight mass spectrometry (GC $\times \mathrm{GC}-\mathrm{TOFMS})$ for the analysis of the irradiated samples $[98,99]$. The 
rac- ${ }^{13} \mathrm{C}$-Ala film was irradiated with L- and R-CPL at 200 and $184 \mathrm{~nm}$, wavelengths at which the electronic $n \rightarrow \pi^{*}$ transitions in the carboxylate anion mixed with the $n\left(\mathrm{COO}^{-}\right) \rightarrow \sigma^{*}(\mathrm{~N}-$ H) transition and the first $\pi \rightarrow \pi^{*}$ transition, occur respectively. The photolysis results showed the remarkable mirror image behavior predicted by the anisotropy spectra: irradiation by L-CPL at $200 \mathrm{~nm}$ yielded an $e e_{L}$ of $+4.19 \%( \pm 0.14 \%)$ and irradiation by R-CPL at the same wavelength yielded an $e e_{L}$ of $-4.22 \%( \pm 0.21 \%)$ reaching similar photolysis rates of $99.97 \%$ and $99.95 \%$, respectively. The irradiation at $184 \mathrm{~nm}$ resulted in the induction of an $e e$ in the opposite direction: L-CPL yielded an $e e_{L}$ of $-3.12 \%( \pm 0.34 \%)$ and R-CPL yielded an $e e_{L}$ of $+3.15 \%( \pm 0.30 \%)$ with photolysis rates of $99.93 \%$ and $99.96 \%$, respectively. These complete mirror results demonstrate that sign and magnitude of the induced ee could be fully controlled by CPL, based on the anisotropy factor $g$.

The experiments to induce an enantiomeric enrichment into amino acids were further extended to the gas-phase. Tia et al. irradiated racemic gas-phase $\alpha$-Ala with circularly polarized synchrotron radiation [100]. The authors selected Lyman- $\alpha(121.6 \mathrm{~nm})$ for their irradiation experiments, which is the dominant photon energy in the interstellar/circumstellar medium (ISM/CSM) and has sufficient energy for the photoionization of $\alpha$-Ala by ejecting photoelectrons from the highest occupied molecular orbital (HOMO) [101]. The authors demonstrated that CPL at Lyman- $\alpha$ could generate an asymmetric flux of gas-phase alanine cations of up to $4 \%$ ee in a given direction via so-called Photoelectron Circular Dichroism (PECD) [102]. This leads to intense enantio-specific forward/ backward asymmetries with respect to the photon axis in the electron emission direction, and therefore of the

385 corresponding recoiling ion.. Such enantio-enriched cations would have then been embedded into asteroids and/or comets, which seeded early Earth with organic material presenting some $e e$. Such a PECD-based photophysical scenario would complement the asymmetric photochemical origin of biomolecular asymmetry, as gas phase chirality transfer from light to matter via PECD is allowed in the strong electric dipole approximation, unlike the much weaker magnetic dipole transitions needed for conventional CD.

\section{Absolute Asymmetric Synthesis of Amino Acids in Simulated Interstellar Ices}

In addition to the photolysis of racemic mixtures of amino acids, the possible absolute asymmetric synthesis of amino acids in ISM environments, especially in molecular clouds, has been discussed. Molecular clouds, the birthplace of stars, are mainly composed of interstellar gases and a minor contribution of dust grains, which comprises $1 \%$ of the total mass of the gases. The temperatures in the molecular clouds are very low $(T<20 \mathrm{~K})$ and most of the volatile molecules (e.g., $\mathrm{H}_{2} \mathrm{O}, \mathrm{CO}, \mathrm{CO}_{2}, \mathrm{CH}_{3} \mathrm{OH}$, and $\mathrm{NH}_{3}$ ) are frozen onto the silicate core by forming ice mantles [103, 104], where UV radiation from stars and energetic cosmic ray particles trigger the formation of more complex organic molecules [103].

\subsection{Synthesis of rac-Amino Acids by Laboratory Simulation of Interstellar Environments}

405 There are a number of experimental studies simulating ISM environments and investigating the formation of organic molecules therein. Most of these laboratory experiments have been conducted in an ultra-high vacuum chamber to simulate the evolution of interstellar ice analogues, which were prepared on a substrate by condensing representative ISM gases at 10-80 K and irradiated with different energy sources [103]. In 2002, Bernstein et al. reported on the formation of three amino acids (Gly, $\alpha$-Ala, and Ser) from a UV/VUV 
irradiated ice mixture composed of $\mathrm{H}_{2} \mathrm{O}$ with various concentrations of $\mathrm{CH}_{3} \mathrm{OH}(5-10 \%$, relative to $\left.\mathrm{H}_{2} \mathrm{O}\right), \mathrm{NH}_{3}(0.5-5 \%)$, and $\mathrm{HCN}(0.5-5 \%)$ at $15 \mathrm{~K}$ [105]. The two chiral amino acids Ala and Ser were racemically produced, which confirmed their indigenous formation. Muñoz Caro et al. demonstrated the formation of 16 amino acids in Lyman- $\alpha$-irradiated interstellar ice analogues at $12 \mathrm{~K}$ [106]. The authors used a gas mixture that contained higher concentrations of other molecules relative to $\mathrm{H}_{2} \mathrm{O}$, compared to Bernstein's work [105], i.e., $\mathrm{H}_{2} \mathrm{O}: \mathrm{CH}_{3} \mathrm{OH}: \mathrm{NH}_{3}: \mathrm{CO}: \mathrm{CO}_{2}=2: 1: 1: 1: 1$ (in mol). The most abundant amino acid formed in both experimental studies was Gly and the simplest chiral amino acids $\alpha$-Ala and Ser. In addition, Muñoz Caro et al. reported that several diamino acids were also formed in relatively high abundances [106]. In later works, Nuevo et al. showed the formation of other biologically relevant proteinogenic amino acids [107]. Some of these amino acids synthesized in the experiments are commonly found in carbonaceous chondrites, including some of the detected diamino acids [108].

High-energy protons are the major component of cosmic rays and Kobayashi et al. irradiated ice mixtures of $\mathrm{H}_{2} \mathrm{O}, \mathrm{NH}_{3}$, and carbon compounds ( $\mathrm{CO}$ or $\mathrm{CH}_{4}$ or propane) with various mixing ratios with $3 \mathrm{MeV}$ protons at $10 \mathrm{~K}$ and $77 \mathrm{~K}$ [109]. The most abundant amino acid in the products was found to be Gly $\left(\mathrm{C}_{2}\right)$, followed by a series of $\mathrm{C}_{3}$ and $\mathrm{C}_{4}$ amino acids: $\alpha$-Ala, $\beta$-Ala, $\alpha$-aminobutyric acid ( $\alpha$-ABA), $\beta$-ABA, $\gamma$-ABA, and $\beta$-aminoisobutyric acid ( $\beta$ AIB). The authors also conducted proton irradiation experiments of gas mixtures at $295 \mathrm{~K}$ and obtained a similar amino acid distribution. Takano et al. conducted further detailed analysis of the amino acid composition of the products of the gas-phase experiments and reported the quantitative yields of 9 proteinogenic and 5 non-proteinogenic amino acids [110]. Related studies used $\gamma$-rays $[111,112]$ and electrons [113] as alternative energy sources relevant to cosmic rays and reported the formation of several amino acids, too.

It should be noted here that most of the amino acids were obtained after acidhydrolysis of the irradiated samples, which indicates that the amino acids might be part of higher molecular weight structures [107, 110]. Recently, Oba et al. performed unique experiments exploiting the $\mathrm{D} / \mathrm{H}$ stable isotopic ratio to understand the formation mechanism of the amino acids and their precursor molecules [114]. The authors used single deuterated 440 methanol $\mathrm{CH}_{2} \mathrm{DOH}$ together with $\mathrm{H}_{2} \mathrm{O}, \mathrm{CO}$, and $\mathrm{NH}_{3}$, with a mixing ratio of 2:5:2:2, to form interstellar ice analogues by irradiating with UV/VUV photons from deuterium lamps in the range $115-170 \mathrm{~nm}$, with two peaks around Lyman- $\alpha$ and $160 \mathrm{~nm}$ at $T=10 \mathrm{~K}$. Samples were analyzed before and after acid-hydrolysis. Five amino acids (Gly, $\alpha$-Ala, $\beta$-Ala, sarcosine (Sar), and Ser) with their deuterated isotopologues whose D atoms bond to carbon atoms were detected. The acid-hydrolysis resulted in a significant increase in the abundances of these 5 amino acids. However, their deuteration level $(\mathrm{D} / \mathrm{H})$ was different. The Ala-group amino acids ( $\alpha$-Ala and $\beta$-Ala) showed significant decrease in $\mathrm{D} / \mathrm{H}$, while the Gly-group (Gly, Sar, and Ser) showed no change. The authors concluded that two different formation mechanisms are involved in the photochemical formation of interstellar amino acids. In their subsequent

450 report, Oba et al. reported significant amount of hexamethylenetetramine $\left(\mathrm{C}_{6} \mathrm{H}_{12} \mathrm{~N}_{4}, \mathrm{HMT}\right)$ in simulated interstellar ice analogues [e.g., 54, 106], could be a source of D-rich alkyl-amines and amino acids [115].

\subsection{Absolute Asymmetric Synthesis of Amino Acids in Interstellar Space}


Investigations on the absolute asymmetric synthesis of amino acids are scarce. Pioneering work was conducted by Nuevo et al. [116, 117]. The authors prepared interstellar ice analogues by depositing a gas mixture $\left(\mathrm{H}_{2} \mathrm{O}:{ }^{13} \mathrm{CH}_{3} \mathrm{OH}: \mathrm{NH}_{3}=1: 1: 1\right)$ onto a cooled substrate at $80 \mathrm{~K}$ and irradiated either with R- or L-CPL at $167 \mathrm{~nm}$. The authors quantified the $e e$ of two chiral amino acids ( $\alpha$-Ala and 2,3-diaminopropanoic acid (2,3-DAP)), but found it to be very low $(<1 \%)$. In a follow-up experiment (Figure 4$)$, a more realistic interstellar ice composition $\left(\mathrm{H}_{2} \mathrm{O}:{ }^{13} \mathrm{CH}_{3} \mathrm{OH}: \mathrm{NH}_{3}=2: 1: 1\right)$ was irradiated with $\mathrm{CPL}$ at $186.7 \mathrm{~nm}$ [118], a wavelength where most of the $\alpha-\mathrm{H}$ amino acids exhibit a maximum CD intensity related to the $n \rightarrow \pi^{*}$ transition [76]. The analysis of the products by enantioselective GC $\times$ GC-TOFMS revealed the production of an $e e=-1.34 \%( \pm 0.40 \%)$, for $\alpha$-Ala with R-CPL irradiation. In subsequent work, Modica et al. produced increased quantities of asymmetrically formed interstellar ice analogues using CPL at 187.9 and $121.6 \mathrm{~nm}$ (Lyman- $\alpha$ ) [119]. The authors identified 16 amino acids and the $e e$ of 5 chiral amino acids ( $\alpha$-Ala, 2,3-DAP, $\alpha$-ABA, Val, and NVal) were determined to range from $-0.20 \%( \pm 0.14 \%)$ to $-2.54 \%( \pm 0.28 \%)$ for L-CPL and from $+0.90 \%( \pm 0.33 \%)$ to $+2.06 \%( \pm 0.34 \%)$ for R-CPL. The sign of the induced ees was found to be identical for all 5 chiral amino acids for a given CPL helicity and wavelength. In addition, the sign of the $e e$ was opposite between 187.0 and $121.6 \mathrm{~nm}$, which is in agreement with the CD and anisotropy spectra of these amino acids $[98,120]$. The authors also showed that the CPL irradiation of the room temperature residues of the interstellar ice analogues resulted in the induction of ees. These results imply that the photochemical induction of an ee by CPL could occur at any stage of the evolution of organic molecules in interstellar ices.

Another asymmetric synthesis experiment of amino acids was conducted by Takano et al. [121]. The authors irradiated first a gaseous mixture of $\mathrm{CO}, \mathrm{NH}_{3}$, and $\mathrm{H}_{2} \mathrm{O}$ with $3.0 \mathrm{MeV}$ protons and obtained complex macromolecular organic molecules. These products of protonirradiation were subsequently irradiated with continuum UV-CPL $(\lambda>200 \mathrm{~nm})$ from a synchrotron radiation source. After the acid-hydrolysis of the products, the authors detected 11 amino acids. The induced $e e$ of alanine was $+0.44 \%( \pm 0.31 \%)$ and $-0.65 \%( \pm 0.23 \%)$ for R- and L-CPL irradiation, respectively, compared to the non-CPL-irradiated sample as the racemic reference $(e e=0.00 \pm 0.35 \%)$.

These laboratory simulation experiments demonstrated that CPL could indeed trigger the induction of a chiral bias into amino acids and their precursors during the evolution of organic molecules in interstellar ices.

\section{Chirality of Amino Acids in Meteorites and Comets}

\subsection{Amino Acids in Meteorites}

Meteorites are the most accessible extraterrestrial samples on the Earth. They can be divided into two major categories, chondrites and non-chondritic meteorites, based on their bulk compositions and textures [122]. Chondrites are remnants of the early solar system and have not experienced melting and planetary differentiation. They are therefore rich in volatile components and exhibit special textures such as chondrules. On the contrary, non-chondritic meteorites have experienced partial or complete melting and planetary differentiation, and chondritic textures erased by these processes [122]. The majority of meteorites are chondrites and originated in asteroids. Carbonaceous chondrites are the most studied class of meteorites due to their significantly high organic carbon content of up to $4 \mathrm{wt} . \%$, most of which exists as insoluble macromolecular material [123]. 
Chemical analyses of amino acids in carbonaceous chondrites gained momentum after the fall of the Murchison meteorite in 1969. The Murchison meteorite was classified as a CM2 (Mighei-type) carbonaceous chondrite based on the bulk chemical composition, mineralogical and petrographic type, and oxygen isotopic compositions [124]. Right after its fall, Kvenvolden et al. reported the existence of 7 amino acids (Gly, $\alpha$-Ala, Methyl-Ala, Sar, Val, Pro, Glu) in Murchison [125]. The research group of Cronin and Pizzarello performed a series of extensive analyses of the Murchison meteorite and detected a diversity of amino acids [126-128]. The two most abundant amino acids are Gly $\left(\mathrm{C}_{2}\right)$ and $\alpha$-AIB $\left(\mathrm{C}_{4}\right)$ and the abundances of other amino acids decreased exponentially with the increase of the carbon number. The amino acids show a large structural diversity and almost all of the possible isomeric forms were confirmed for the $\mathrm{C}_{2}$ to $\mathrm{C}_{7} \alpha$-amino acids. Among them, $\alpha$-branched isomers were the most abundant, with the abundances decreasing in the order $\alpha>\gamma>\beta$. The branched carbon chain isomers were predominant and the straight chain isomers were the least abundant. The amount of free amino acids is rather low and most amino acids are released from precursor structures by acid-hydrolysis. These amino acids can be grouped into two categories: monoamino monocarboxyl acids (e.g., Ala) and monoamino dicarboxyl acids (e.g., Asp), including related $\mathrm{N}$-alkyl derivatives and cyclic amino acids. Later on, the discovery of diamino acids (e.g., 2,3-DAP) by Meierhenrich et al. added a new class to the Murchison amino acids [108]. Recently, Koga and Naraoka discovered racemic mixtures of 10 new hydroxyl amino acids [129]. Up to now, 96 species of amino acids, which comprise $\alpha$, $\beta, \gamma$ and $\delta$ isomers of the carbon numbers between $\mathrm{C}_{2}$ and $\mathrm{C}_{9}$ including dicarboxyl and diamino functional groups, were identified in the Murchison meteorite [129] (Figure 5).

The analysis of other carbonaceous chondrites, including many Antarctic meteorites, revealed that the amino acid composition of the Murchison meteorite cannot be considered to be universal but that there is a certain variation among different carbonaceous chondrites [130]. For example, the most abundant amino acid in CI chondrites, such as Ivuna and Orgueil, is $\beta$-Ala, compared to the $\alpha$-amino acids that are predominant in the Murchison meteorite [131]. The thermally altered chondrites such as CV and CO are rich in straight chain, amino-terminal acids ( $n$ - $\omega$-amino acids) [132-134]. Furthermore, the aqueously altered

530 CR2 chondrites were found to contain the highest total amino acid concentrations, which are 250 ppm for the Graves Nunataks (GRA) 95229 meteorite and 180 ppm for the Elephant Moraine (EET) 92042 meteorite [135]. For comparison, the total amino acid concentration of the Murchison meteorite is 14-21 ppm [131]. The major amino acids in the two CR2 chondrites are the $\alpha$ - amino acids $\alpha$-AIB, Gly, $\alpha$-Ala, and iVal [135]. Aqueous alteration on

535 the meteoritic parent body has also been proposed to influence the abundances of amino acids, as well as their relative distribution $[131,136,137]$. The variations in the amino acid composition among carbonaceous chondrites imply different formation and/or degradation pathways of meteoritic amino acids in the meteorite parent bodies and/or before their formation in the presolar nebula. The extraterrestrial isotopic signatures of meteoritic amino 540 acids (nitrogen, carbon, and hydrogen) may provide potential clues to their molecular evolution [138-140].

\subsection{Amino Acids in Comets}


The synthesis of a variety of amino acids in simulated interstellar ice analogues, as discussed in the previous chapter, suggests amino acids and other organic compounds to be present in comets. However, the in situ detection of amino acids in comets is difficult due to the limited sampling feasibility. Astronomical observations in search of the amino acid Gly of comet Hale-Bopp and Hyakutake was unsuccessful [141].

The National Aeronautics and Space Administration (NASA)'s Stardust mission was the first mission that succeeded in returning pristine cometary dust samples from comet 81P/Wild 2 to Earth [142]. The amino acid analysis of the returned sample reported on the possible detection of Gly [143]. The authenticity of this detection is still under discussion due to the terrestrial contamination of the collector aerogel. The European Space Agency (ESA)'s Rosetta Mission was the first to achieve landing on the nucleus of a comet and provided

555 pioneering insights on the morphology and chemical composition of its target 67P/Churyumov-Gerasimenko [144]. After the touchdown of Philae on the cometary surface on November $12^{\text {th }}, 2014$, both the gas release system ADS (Active Descent System) and the two anchoring harpoons did not operate as expected. Philae bounced in the low gravity environment and eventually landed after a two hour 'hop' in an unforeseen area of the cometary nucleus [145]. As a consequence of the unexpected 'vertical' landing of Philae it was not possible to collect a sufficient amount of a cometary surface sample by the instrument $\mathrm{SD}^{2}$ (Sample Drilling and Distribution) for the Philae's enantioselective gas chromatograph COSAC (Cometary Sampling and Composition). However, the in situ analysis of the cometary volatiles by Rosetta's on-board mass spectrometer ROSINA (Rosetta Orbiter Spectrometer for Ion and Neutral Analysis) detected a molecule with a mass number of 75 Dalton, which indicates the presence of Gly $\left(\mathrm{C}_{2} \mathrm{H}_{5} \mathrm{NO}_{2}\right)$ and/or other structural isomers having the same chemical formula and mass numbers (cf. [114]) [146].

\subsection{Chirality of Amino Acids in Meteorites}

The enantiomeric excesses in amino acids found in carbonaceous chondrites is still a controversial issue due to the analytical challenges to resolve meteoritic amino acid enantiomers in highly complex samples from the potential terrestrial contamination of meteorites. The first enantioselective analysis of the Murchison amino acids was performed shortly after its fall and revealed that the chiral amino acids were racemic [125, 147]. The non-proteinogenic $\alpha$-methyl amino acids that are distinctive to meteorites (e.g., iVal) were also reported to be racemic [148]. The analysis of the Murray meteorite (CM2), which fell in 1950, also revealed racemic amino acids [149]. The racemic distribution of meteoritic amino acids was argued to be an indicator of the indigeneity of the results and the negligible level of terrestrial contamination.

In subsequent studies, various degrees of ees in amino acids from different meteorite groups have been reported. The significant L-excess $\left(e e_{\mathrm{L}}\right)$ in the Murchison proteinogenic amino acids (e.g., $18.9 \%( \pm 4.2 \%)$ for $\alpha$-Ala, $51.3 \%( \pm 4.9 \%)$ for Glu) reported by Engel and Nagy [e.g., 150] turned out to be terrestrial contribution and analytical artefacts [151, 152]. Cronin and Pizzarello later reported on slight to moderate degrees of $e e_{\mathrm{L}}$ in several nonin the Murchison values of 2.8-9.2\% ( $\pm 0.3-1.3 \%)$, and in Murray values of 1.0-6.0\% $( \pm 0.3-$ $0.7 \%$ ), were reported for $\alpha$-methyl Ile, $\alpha$-methyl alloisoleucine ( $\alpha$-methyl-allo-Ile), 2 -amino- 
2,3-dimethylpentanoic acid (2-a-2,3-DMPA), iVal, $\alpha$-methyl-NVal, $\alpha$-methyl-Val, and $\alpha$ methyl-NLeu $[151,153]$. The reported $e e_{\mathrm{L}}$ of proteinogenic amino acids ( $\alpha$-Ala and Val) were relatively small $(1.2-2.2 \%( \pm 0.3-0.6 \%))$ in this study. The authors argued that the $e e_{\mathrm{L}}$ in meteoritic $\alpha$-methyl amino acids compared to the racemic $\alpha$-H amino acids could be explained by the resistance to racemization of the $\alpha, \alpha$-dialkyl amino acids. In addition, Pizzarello et al. showed a heterogeneous distribution of $e e_{\mathrm{L}}$ of $\mathrm{iVal}$ in several fragments and even among one fragment of the Murchison and Murray meteorites [154]. The relative abundances of iVal to Ala (iVal/Ala) varied between 0.5 and 6.5. The authors discussed that the heterogeneity of iVal correlates well with the distribution of hydrous silicates and thus, the $e e_{\mathrm{L}}$ of meteoritic amino acids may have been produced by a secondary process in the meteoritic parent bodies. Glavin and Dworkin further analyzed several different types of carbonaceous chondrites (CI, CM, and CR) targeting the $\mathrm{C}_{5}$ Val series of amino acids (Val, $600 \mathrm{iVal}, \mathrm{NVal})$ and reported a large $e e_{\mathrm{L}}$ in iVal of Orgueil (CI1, 15.2\% ( $\left.\pm 4.0 \%\right)$ ) and Murchison $(\mathrm{CM} 2,18.5 \%( \pm 2.6 \%)$ ) meteorites, while iVal was found to be racemic in QUE 99177 and EET 92042 CR2 chondrites [155]. The large $e e_{\mathrm{L}}$ in iVal is proposed to be the result of chiral amplification by aqueous alteration on the parent bodies. Aqueous alteration was also argued to cause the observed heterogeneity of the relative abundances of amino acids among 605 different carbonaceous chondrites [156].

The difficulty of the enantioselective analysis of meteoritic amino acids arises from the high sample diversity but low concentration of each molecule present in meteorites. The enantioselective analysis of meteoritic amino acids requires several steps: 1) extraction from a powdered meteorite sample, 2) acid-hydrolysis, 3) fractionation by ion exchange column 610 chromatography, 4) adequate derivatization, 5) separation on chiral GC or LC columns and 6) their final detection and quantification. Baseline separation of each enantiomeric pair is critical for the precise determination of any ee. Moreover, the derivatization method has to be carefully chosen to avoid the formation of artefacts as discussed by Ohkouchi et al. [157]. The conventional mono-dimensional GC or LC techniques show limitations for the quantitative

615 separation of molecules with similar chromatographic properties, and the development of comprehensive multidimensional GC and/or LC systems coupled to very sensitive detectors has enabled some of these limitations to be overcome. Myrgorodska et al. applied enantioselective $\mathrm{GC} \times \mathrm{GC}-\mathrm{TOFMS}$ to the analysis of amino acids extracted from the Murchison meteorite [158]. Using the improved resolving power of enantioselective $\mathrm{GC} \times \mathrm{GC}$ 620 [159], racemic to small $e e_{\mathrm{L}}$, up to $5.95 \%( \pm 0.62 \%)$ for non-proteinogenic and proteinogenic amino acids with exceptions of one negative $e e_{\mathrm{L}}$ value $-9.55 \%( \pm 0.70 \%)$ for allo-Ile, were reported. High values of two proteinogenic amino acids were found to be considerably enriched in the naturally occurring L-enantiomer, namely Ile and Leu with $e e_{\mathrm{L}}$ values of $9.49 \%( \pm 1.16 \%)$ and $26.33 \%( \pm 0.76 \%)$, respectively. The $e e_{\mathrm{L}}$ of $\alpha$-Ala was $3.16 \%( \pm 0.80 \%)$, Val $4.88 \%( \pm 0.73 \%)$, and iVal $4.61 \%( \pm 0.83 \%)$. No significant difference in the $e e_{\mathrm{L}}$ values between $\alpha-\mathrm{H}$ and $\alpha$ - methyl amino acids have been observed, which is in contrast to previous reports. An innovative analytical technique by Hamase et al. has cast a new light on the controversy of the meteoritic $e e_{\mathrm{L}}$ [160]. The authors developed a two-dimensional chiral highperformance liquid chromatographic (2D-HPLC) system, initially aiming for the analysis of 630 trace levels of D-amino acids in mammals [30, 32, 34, 161]. In the 2D-HPLC system, analytes are separated on an achiral reversed-phase column in the first dimension where 
targeted amino acids are collected on-line in a multi-loop device. Afterwards, they are automatically injected onto a chiral column in the second dimension and detected by a fluorescence detector. Prior to the 2D-HPLC analysis, the amino acids were derivatized with 4-fluoro-7-nitro-2,1,3-benzoxadiazole (NBD-F). The authors applied this technique to extraterrestrial amino acids from Yamato 791191, an Antarctic CM2 meteorite. The enantioselective analysis of a total of 8 chiral amino acids, including 2 proteinogenic ( $\alpha$-Ala, Val) and 6 non-proteinogenic ( $\alpha$-ABA, NVal, $N$-methyl-Ala, iVal, $\beta$-ABA and $\beta$-AIB) amino acids, revealed an overall racemic distribution. These new data on the $e e_{\mathrm{L}}$ of meteoritic amino acids will stimulate further investigations on the origin and formation processes of chiral amino acids in extraterrestrial samples.

As summarized above, the chirality of amino acids in meteorites is still a highly debated subject, with controversy among the reported ee values. Complementary data, such as the in situ and ex situ analyses of pristine asteroidal or cometary samples by sample return missions, are necessary to ultimately prove the origin of left-handed amino acids in extraterrestrial environments. This topic is further discussed in Chapter 6.

\section{Delivery of Organic Molecules by Comets and Asteroids and the Amplification of $e e$}

For the delivery of chiral amino acids from extraterrestrial bodies, such as comets and asteroids, the impact shock at the entry to the early Earth is an inevitable step. The shock wave generated at the impact creates extremely high pressure and temperature conditions, which are assumed to influence the organic molecules inside the meteorite. Therefore, the effects of impact shocks on the distribution of amino acids have been intensively studied in order to examine the feasibility of an extraterrestrial delivery of amino acids towards Earth. Since organic molecules are generally labile to heat, the thermal decomposition and racemization of amino acids is one of the major concerns regarding their chemical integrity.

\subsection{Constraints for the Delivery of Extraterrestrial Chiral Amino Acids}

The earliest shock experiments performed by Tingle et al. used samples from the Murchison meteorite [162]. The authors gave impact shocks, with a pressure of $36 \mathrm{GPa}$ generated by a solid propellant gun, to polished pieces of a Murchison sample and reported that $70 \%$ of the organic species in the meteorites were decomposed by the impact shock. Sekine et al. reported that dehydration and carbonization of organic materials started already at pressures of 7-8 GPa [163]. They concluded that heat generated by impact shock could be a major factor that controls the alteration.

A shock experiment that focused on amino acids was first conducted by Peterson et al. [164]. In this study, several amino acids were mixed with the mineral matrices of powdered Murchison (CM2) and Allende (CV3) meteorites and subjected to impact shocks up to 32

$670 \mathrm{GPa}$. The authors reported on the decomposition of most of the amino acids at approximately $20 \mathrm{GPa}$ with the formation of secondary amino acids. Sugahara and Mimura showed that 4 amino acids (Gly, $\alpha$-Ala, $\alpha$-ABA, $\alpha$-AIB), which had been mixed with serpentine powder to imitate the carbonaceous chondrite matrix, decomposed rapidly by $92-95 \%$ at $18.4 \mathrm{GPa}$ and almost fully decomposed at $35.3 \mathrm{GPa}$ [165]. The results indicate that the shock decomposition of amino acids is a dynamic and rapid process and independent from the chemical structure of 
the amino acids. The critical shock pressure of the decomposition of amino acids is consistent among several studies and is about 18-20 GPa.

The racemization of amino acids by impact shock is another important concern regarding the delivery of chiral amino acids to the early Earth. Using enantiopure amino acids, Peterson et al. found that racemization proceeds slower than decomposition of amino acids via the shock experiments [164]. The authors showed that racemization did not occur until 7 GPa and the chirality was retained at $>60 \%$ even after $>99 \%$ decomposition of the original amino acids at $25 \mathrm{GPa}$.

Since decomposition occurs faster than racemization, the major constraints for the delivery of chiral amino acids depend on the conditions of the decomposition. As discussed above, the shock pressure of 18-20 GPa would be one of the important constraints. If we consider the vertical oceanic impacts of carbonaceous asteroids or comets, this shock pressure range corresponds to an impact velocity of $<5 \mathrm{~km} / \mathrm{s}$ for carbonaceous asteroids and $<6 \mathrm{~km} / \mathrm{s}$ for comets, based on Hugoniot data [e.g., 166, 167]. These impact velocities were relatively low compared with the average impact velocities of asteroids $(15 \mathrm{~km} / \mathrm{s})$ [168] and shortperiod comets $(24 \mathrm{~km} / \mathrm{s})$ [169]. However, there are several factors related to natural asteroidal and cometary impacts that can reduce the shock pressure dramatically. These factors were discussed in detail by Sugahara and Mimura [170], underlining that oblique impact, deceleration, and fragmentation in the atmosphere could contribute effectively to reduce the shock pressure to below $20 \mathrm{GPa}$. Furukawa et al. provided a detailed discussion about decomposition and racemization of amino acids in relation to the various heat production processes at impact shock [171].

On the other hand, impacts can also act as a driving force for molecular evolution. Sugahara and Mimura demonstrated that comet impacts could oligomerize amino acids to form peptides up to tri-peptides by shock experiments on frozen mixtures of amino acids, water ice, and silicate (forsterite) at $77 \mathrm{~K}[170,172]$. Shock experiments on cometary ice analogues by Martins et al. revealed the synthesis of amino acids [173]. A theoretical study predicted the synthesis of a Gly-containing molecule by impact shock [174]. Thus, extraterrestrial impacts do not always result in the complete decomposition of amino acids.

\subsection{Amplification of $e e$ in Terrestrial or Extraterrestrial Environments}

In the previous chapters, we discussed the symmetry breaking of amino acids by CPL and their possible delivery by extraterrestrial impacts. However, the inducible ee by CPL that could have been delivered to early Earth after surviving the impact shock would have been

710 very small. Soai et al. proposed the enhancement of such small initial ee by asymmetric autocatalysis [175]. They demonstrated that the small ee (2\%) of chiral 5-pyrimidyl alkanol was increased significantly $(88 \%)$ by the autocatalytic reaction involving diisopropylzinc and pyrimidine-5-carboxaldehyde. Kawasaki et al. further investigated this autocatalytic reaction [176]. They started the experiments by irradiating racemic pyrimidyl alkanol with CPL $(\lambda=$ $715290-390$ or $313 \mathrm{~nm}$ ), followed by chiral amplification of the initial small ee by asymmetric autocatalysis to obtain nearly enantiopure $(>99.5 \% e e$ ) compounds. Moreover, the same research team demonstrated that chiral deuterated Gly (Gly- $\alpha-\alpha)$, $\alpha$-methyl-Ala ( $\alpha$-methyl- $d_{3}-$ $\mathrm{Ala}$ ), and even carbon isotopically chiral alcohols, in which the relative energetic difference 
between ${ }^{13} \mathrm{C}$ and ${ }^{12} \mathrm{C}$ is smaller compared to the relative energetic ratio between $\mathrm{D}$ and $\mathrm{H}$, can be used as chiral initiators for asymmetric autocatalysis [177, 178].

Another proposed scenario includes an extended Viedma model that combines CPL irradiation and Viedma ripening [e.g., 179], and the chirality transfer from a chiral methyl-Val to proteinogenic amino acids (Phe) during their synthesis with a copper catalyst [180].

\section{Perspective for the Upcoming Space Missions}

Space missions have significantly advanced our knowledge about the Solar System in the last decades. Extraterrestrial samples, such as meteorites and interplanetary dust particles (IDPs), collected on the Earth cannot fully exclude the risk of terrestrial contamination. They are also considered to have been affected to some extent by impact shock during entry. Sample return missions have therefore the great advantage to obtain pristine matter with limited terrestrial contamination and the record of the original locality.

\subsection{Sample Return Missions: Hayabusa2, OSIRIS-REx, and MMX}

Currently, two major sample return missions Hayabusa2 and OSIRIS-Rex are ongoing. Hayabusa2 is the second sample return mission from an asteroid (Figure 7a), following Hayabusa, the first successful sample return mission of the Japanese Aerospace Exploration Agency (JAXA). Although the sampling mechanism of Hayabusa failed and terrestrial contamination has been revealed, few authentic particles from the targeted asteroid Itokawa have been returned. Initial chemical and mineralogical analysis of these asteroidal grains provided unprecedented information on the formation and evolutional history of the asteroid [e.g., 181-185]. The Hayabusa2 spacecraft was successfully launched on December 3, 2014 and is now heading for the near-Earth carbonaceous-type (C-type) asteroid (162173) Ryugu. Hayabusa 2 is scheduled to arrive at Ryugu in the middle of 2018, collect at least $100 \mathrm{mg}$ of surface samples at multiple places, and return the asteroidal samples to Earth at the end of 2020. One of the scientific goals of Hayabusa2 focuses on the origin and evolution of volatile components in the early Solar System and in the asteroidal parent body [186, 187]. For this purpose, on-site geological observations of the asteroid by remote sensing from the spacecraft in the $\mathrm{km}$ to $\mathrm{mm}$ scale will be linked to the in situ surface measurements by the lander and with the analyses of the retuned samples (atomic scale).

OSIRIS-REx is a NASA sample return mission from an asteroid (Fig. 7b). The OSIRIS-REx spacecraft was successfully launched on September 8, 2016. The target asteroid is the B-type near-Earth asteroid Bennu, belonging to a rare spectral subgroup of carbonaceous asteroids [188]. OSIRIS-REx is planning to arrive at Bennu in mid-2018 and to return at least $60 \mathrm{~g}$ of asteroid regolith sample in the middle of 2023. OSIRIS-REx shares scientific goals with Hayabusa2. The prime objective of the mission is to understand the role of organic matter and water in primitive asteroids and their impact on the origin and early evolution of life on Earth. Thus, the synergetic comparison of the collected data of both sample return missions is expected to considerably advance our understanding of the evolution of organic molecules in space [186].

In both sample return missions, the lessons learned from the past sample return missions will be utilized. A critical concern in sample return missions is the elimination of 
terrestrial contamination. For the Stardust mission and its returned cometary grains, a comprehensive assessment of the terrestrial contamination throughout the mission was preformed [189]. However, the terrestrial contamination, in which $\varepsilon$-amino- $n$-caproic acid (EACA) that originated from Nylon-6 of the shipping bags [190] was found in the sampling aerogel, has questioned the unambiguous detection of Gly in the returned cometary grains [143] (see also Chapter 4). In the case of the Hayabusa mission, an assessment of the contamination of the curation facilities was performed [191]. The analyses of organic compounds, including amino acids in 5 individual carbonaceous (category 3$)$ particles ( 50 to $100 \mu \mathrm{m}$ in diameter) resulted in no detection of organic molecules $[192,193]$. The carbonaceous matter recovered from Hayabusa's sample container turned out to be of terrestrial origin, potentially including contamination from the spacecraft and the sampling processes [e.g., 194, 195]. The knowledge obtained from the first Hayabusa mission has been used to design the follow-up Hayabusa2 sampling system [196, 197]. In addition, comprehensive analyses of terrestrial contamination pathways, including the chirality of molecules, have been systematically conducted for both Hayabusa2 and OSIRIS-Rex missions to accumulate extensive knowledge about potential contamination sources [198, 199].

780 JAXA is planning a new mission named MMX (Martian Moon eXplorer) that will explore the Martian moons Phobos and Deimos (Fig. 7c). The aim of this mission is to reveal the formation processes of the Martian moons and to understand the delivery processes of water and organics to the inner planets [200, 201]. In this mission, a lander is to be sent to the surface of Phobos that will sample the surface using a robot arm and return these samples back to Earth. The spacecraft is expected to be launched in the early 2020's.

\subsection{In Situ Analysis: ExoMars 2020}

Another space mission aims for the in situ analysis of organic matter. ESA's ExoMars 2020 mission will be launched in 2020 and plans to deposit a lander - the ExoMars rover - on the Martian surface, that is equipped with a drilling system and several instruments for atmospheric and geophysical/chemical analysis [202] (Figure 7d). The main scientific targets of the ExoMars 2020 mission are the search for physical and chemical biosignatures of extinct life as well as for abiotic/prebiotic organics that indicate a habitability past of Mars. The Mars Organic Molecule Analyzer (MOMA) on board the ExoMars rover was designed for this

795 purpose [203, 204]. MOMA is the largest instrument on the rover and able to analyze a wide range of organic compounds with high sensitivity. Subsurface samples will be provided by drilling down to $2 \mathrm{~m}$ below the Martian surface. This is what distinguishes the ExoMars 2020 mission from previous Mars missions. Organic compounds in Martian subsurface samples will be volatilized and analyzed by a mass spectrometer that allows for the operation in two different modes: (1) The Gas Chromatography-Mass Spectrometry (GCMS) mode and (2) the Laser Desorption Mass Spectrometry (LDMS) mode. The GCMS will allow the sample to be heated for evaporation and/or thermochemical decomposition (pyrolysis), so that the organic compounds can be further derivatized by chemical reagents and separated on different GC columns. The LDMS mode will promote the prompt desorption of organic molecules into the gas phase by intense UV laser pulses followed by their direct analysis using MS. For the GCMS mode, two derivatization reagents are prepared, $N, N$-methyl-test-butyl- 
dimethylsilyltrifluoroacetamide (MTBSTFA) and $N, N$-Dimethylformamide dimethyl acetal (DMF-DMA), which allow for the derivatization of organic molecules that contain a labile polar functional group, e.g., $-\mathrm{OH},-\mathrm{COOH},-\mathrm{NH},-\mathrm{SH}$, or -PH, including amino acids. MOMA

810 is equipped with a chiral capillary column (CP Chirasil Dex CB) that enables the resolution of enantiomers.

One critical concern of space missions aiming for in situ analysis on planetary bodies is terrestrial contamination imported by the rover and/or spacecraft. NASA's Mars Science Laboratory (MSL) mission that operated the Curiosity rover on Mars has implemented

815 strategies to control and reduce the risk of contamination in the process of exploration [205, 206]. MSL reported that organic compounds unintentionally originated from a reagent brought to Mars to allow for the detection of organic volatiles in Martian soil [207]. Precautions and assessing the characteristics of organic contamination prior to each mission are therefore necessary to avoid false positive detection of biomolecules and to fulfil 820 planetary protection regulations.

\subsection{Perspective}

We have outlined how CPL can induce $e e$ in amino acids by asymmetric photolysis and asymmetric synthesis. The series of experimental results using circularly polarized 825 synchrotron radiation in combination with the CD and anisotropy data of amino acids have confirmed the ability of CPL to induce an initial enantiomeric imbalance into interstellar/circumstellar organic molecules. Thus, it is a possible scenario that amino acids with a reasonably small $e e$ induced by CPL became incorporated into comets and asteroids, being delivered to the early Earth, where they have triggered subsequent chiral amplification

830 in suitable terrestrial environments. However, the analyses and interpretation of meteoritic ees remains controversial due to the potential terrestrial contamination and analytical challenges. The analyses of pristine asteroid samples obtained by the Hayabusa2 and OSIRIS-REx sample return missions and the in situ analyses on Mars by the ExoMars 2020 mission, as well as the MMX mission to Martian moons, are considered to be highly important to provide

835 solid evidence about the optical purity of organic molecules, especially amino acids in extraterrestrial materials. The obtained data are expected to give crucial insights into the linkage between extraterrestrial organic molecules and the origins of biomolecular homochirality.

\section{Acknowledgements}

This work was funded by the JSPS Overseas Research Fellowships (H.S) and a Grantin-Aid for Scientific Research on Innovative Areas (Research Project on Evolution of Molecules in Space, No. 25108006 : H.S. and Y.T.). We thank the Agence National de la 845 Recherche for support under grant number ANR-16-C829-0015. This work was furthermore funded by the French Government and the Agence National de la Recherche, Investissement d'Avenir UCA ${ }^{\mathrm{JEDI}}$ (ANR-15-IDEX-01).

\section{$850 \quad$ Figures and Figure Captions}


Fig. 1. Representation of right-handed circularly polarized light (R-CPL). The direction of the magnetic field vector is perpendicular to the electric field vector shown in green arrow.

Fig. 2. Circular dichroism (CD) (a) and anisotropy ( $g$ ) spectra (b) of D-amino acids in their amorphous solid-state in the VUV and UV region (modified from Meinert et al. [85]).

Fig. 3. Anisotropy spectra of L- and D-alanine in VUV and UV region (a), and the GC $\times$ GC chromatograms of $\mathrm{rac}-\left[{ }^{13} \mathrm{C}\right]$ alanine films that were irradiated with $\mathrm{L}$ - and R-CPL at wavelengths of 200 and $184 \mathrm{~nm}$ (b) (modified from Meinert et al. [98]). The induced ee 860 showed the opposite signs between 200 and $184 \mathrm{~nm}$, which are closely correlated with the reserved signs in the anisotropy spectra.

Fig. 4. Experimental setup for asymmetric synthesis of amino acids in interstellar ice analogues (modified from Meinert et al. [208]). The representative interstellar (ISM) gas molecules are deposited on an $\mathrm{MgF}_{2}$ window at $80 \mathrm{~K}$ in the center of the high vacuum chamber. VUV-CPL from a synchrotron light source irradiates the ice sample on the $\mathrm{MgF}_{2}$ window. During the experiments, in situ IR-spectra are taken to monitor the composition and the thickness of the ice. After the irradiation, the sample is warmed up to room temperature and the remaining residue analyzed by enantioselective gas chromatography.

Fig. 5. Structures of major extraterrestrial amino acids up to $\mathrm{C}_{6}$ in carbonaceous chondrites.

Fig. 6. Flow diagram of the two-dimensional chiral high-performance liquid chromatography (2D-HPLC) system (a), and the enantiomeric separation of amino acids in the Yamato 791191 875 meteorite by the 2D-HPLC system (b) (modified from Hamase et al. [160]). The grey bars in the first dimension chromatogram indicate the on-line collected fractions via a multi-loop device that are transferred to the enantioselective second dimension column.

Fig. 7. Mission image of Hayabusa2 (a), OSIRIS-REx (b), MMX (c), and ExoMars 2020 (d) (image courtesy of JAXA for (a) and (c), NASA for (b), and ESA for (d), respectively). 


\section{Reference}

[1] T.D. Lee, C.N. Yang, Question of parity conservation in weak interactions, Phys. Rev. 104 (1956) 254-258.

885

[2] M. Quack, How Important is Parity Violation for Molecular and Biomolecular Chirality?, Angew. Chem. Int. Ed. 41 (2002) 4618-4630.

[3] W.A. Bonner, Parity violation and the evolution of biomolecular homochirality, Chirality 12 (2000) 114-126.

[4] J.K. Laerdahl, R. Wesendrup, P. Schwerdtfeger, D- or L-Alanine: That is the question, Chem. Phys. Chem. 1 (2000) 60-62.

[5] A.J. MacDermott, T. Fu, G.O. Hyde, R. Nakatsuka, A.P. Coleman, The effect of parity violation on kinetic models of enantioselective autocatalysis, Orig. Life Evol. Biosph. 39 (2009) 407-437.

[6] K.H. Schleifer, O. Kandler, Peptidoglycan types of bacterial cell walls and their taxonomic implications, Bacteriol. Rev. 36 (1972) 407-477.

[7] W. Vollmer, D. Blanot, M.A. de Pedro, Peptidoglycan structure and architecture, FEMS Microbiol. Rev. 32 (2008) 149-167.

[8] H. Lam, D.-C. Oh, F. Cava, C.N. Takacs, J. Clardy, M.A. de Pedro, M.K. Waldor, Damino acids govern stationary phase cell wall remodeling in bacteria, Science 325 (2009)

[9] J.J. Corrigan, D-Amino acids in animals, Science 164 (1969) 142-149.

[10] A. D'Aniello, D-Aspartic acid: An endogenous amino acid with an important neuroendocrine role, Brain Res. Rev. 53 (2007) 215-234.

905 neuroendocrine systems, Amino Acids 43 (2012) 1873-1886.

[12] A. D'Aniello, A. Giuditta, Identification of D-aspartic acid in the brain of Octopus vulgaris Lam, J. Neurochem. 29 (1977) 1053-1057.

[13] A. D'Aniello, A. Giuditta, Presence of D-aspartate in squid axoplasm and in other regions of the cephalopod nervous system, J. Neurochem. 31 (1978) 1107-1108.

910 [14] E. Okuma, H. Abe, Simultaneous determination of D- and L-amino acids in the nervous tissues of crustaceans using precolumn derivatization with (+)-1-(9 fuorenyl)ethyl chloroformate and reversed-phase ion-pair high-performance liquid chromatography, J. Chromatogr. B 660 (1994) 243-250.

[15] P. Spinelli, E.R. Brown, G. Ferrandino, M. Branno, P.G. Montarolo, E. D'Aniello R.K. Rastogi, B. D'Aniello, G.C. Baccari, G. Fisher, A. D'Aniello. D-Aspartic acid in the nervous system of Aplysia limacina: possible role in neurotransmission, J. Cell. Physiol. 206 (2006) 672-681.

[16] Y. Kera, S. Hasegawa, T. Watanabe, H.Segawa, R. Yamada, D-Aspartate oxidase and free acidic D-amino acids in fish tissues, Comp. Biochem. Physiol. 119B (1998) 95-100.

920 [17] F. Raucci, A .Santillo, A. D'Aniello, P. Chieffi, G.C.Baccari, D-Aspartate modulates transcriptional activity in Harderian gland of frog, Rana Esculenta: Morphological and molecular evidence, J. Cell. Physiol. 204 (2005) 445-454.

[18] L. Assisi, V. Botte1, A. D’Aniello, M.M. Di Fiore, Enhancement of aromatase activity by D-aspartic acid in the ovary of the lizard Podarcis s. sicula, Reproduction 121 (2001), 925 803-808.

[19] A. Neidle, D.S. Dunlop, Developmental changes in free D-aspartic acid in the chicken embryo and in the neonatal rat, Life Sci. 46 (1990) 1517-1522.

[20] H. Han, Y. Miyoshi, R. Koga, M. Mita, R. Konno, K. Hamase, Changes in D-aspartic acid and d-glutamic acid levels in the tissues and physiological fluids of mice with various d-aspartate oxidase activities, J. Pharm. Biomed. Anal. 116 (2015) 47-52. 
[21] M. Katane, H. Homma, D-Aspartate-An important bioactive substance in mammals: A review from an analytical and biological point of view, J. Chromatogr. B 879 (2011) $3108-3121$

[22] T. Nishikawa, Analysis of free D-serine in mammals and its biological relevance, J. Chromatogr. B 879 (2011) 3169-3183.

[23] H. Abe, E. Okuma, H. Amano, H. Noda, K. Watanabe, Role of free D- and L-alanine in the Japanese mitten crab Eriocheir japonicus to intracellular osmoregulation during downstream spawning migration, Comp. Biochem. Physiol. Part A 123 (1999) 55-59.

[24] E. Okuma, E. Fujita, H. Amino, H. Noda, H. Abe, Distribution of free D-amino acids in the tissues of crustaceans, Fish. Sci. 61 (1995) 157-160.

[25] A. D'Aniello, A. Giuditta. Presence of D-alanine in crustacean muscle and hepatopancreas. Comp. Biochem. Physiol. Part B 66 (1980) 319-322.

[26] E. Okuma, K. Watanabe, H. Abe, Distribution of free D-amino acids in bivalve mollusks and the effects of physiological conditions on the levels of D and L-alanine in the tissues of the hard clam, Meretrix lusoria, Fish. Sci. 64 (1999) 606-611.

[27] T. Nishikawa, Metabolism and functional roles of endogenous D-serine in mammalian brains, Biol. Pharm. Bull 28 (2005) 1561-1565.

[28] H. Mori, R. Inoue, Serine racemase knockout mice, Chem. Biodivers. 7 (2010) 15731578.

950 [29] C.A. Weatherly, S. Du, C. Parpia, P.T. Santos, A.L. Hartman, D.W. Armstrong, DAmino acid levels in perfused mouse brain tissue and blood: A comparative study, ACS Chem. Neurosci. 8 (2017) 1251-1261.

[30] Y. Miyoshi, T. Oyama, Y. Itoh, K. Hamase, Enantioselective two-dimensional highperformance liquid chromatographic determination of amino acids; Analysis and physiological significance of D-amino acids in mammals, Chromatogr. 35 (2014) 49-57.

[31] H. Brückner, A. Schieber, Determination of amino acid enantiomers in human urine and blood serum by gas chromatography-mass spectrometry, Biomed. Chromatogr. 15 (2001) $166-172$.

[32] M. Ariyoshi, M. Katane, K. Hamase, Y. Miyoshi, M. Nakane, A. Hoshino, Y. Okawa, Y. Mita, S. Kaimoto, M. Uchihashi, K. Fukai, K. Ono, S. Tateishi, D.Hato, R. Yamanaka, S. Honda, Y. Fushimura, E. Iwai-Kanai, N. Ishihara, M. Mita, H. Homma, S. Matoba, DGlutamate is metabolized in the heart mitochondria, Nat Sci Rep 7 (2017) 43911.

[33] I. Kaneko, N. Yamada, Y. Sakuraba, M. Kamenosono, S. Tutumi, Suppression of mitochondrial succinate dehydrogenase, a primary target of B-Amyloid, and its derivative racemized at ser residue, J. Neurochem. 65 (1995) 2585-2593.

[34] T. Kimura, K. Hamase, Y. Miyoshi, R. Yamamoto, K. Yasuda, M. Mita, H. Rakugi, T. Hayashi, Y. Isaka, Chiral amino acid metabolomics for novel biomarker screening in the prognosis of chronic kidney disease, Nat. Sci. Rep. 6 (2016) 26137.

[35] N. Fujii, T Kaji, N. Fujii, D-Amino acids in aged proteins: Analysis and biological relevance, J. Chromatogr. B 879 (2011) 3141-3147.

[36] C. Ishii, T. Miyamoto, S. Ishigo, Y. Miyoshi, M. Mita, H. Homma, T. Ueda, K. Hamase, Two-dimensional HPLC-MS/MS determination of multiple D-amino acids residues in the proteins stored under various $\mathrm{pH}$ conditions, Chromatogr. 38 (2017) 65-73.

[37] K. Soai, S. Osanai, Kadowaki, S. Yonekubo, T. Shibata, I. Sato, $d$ - and $l$-QuartzPromoted Highly Enantioselective Synthesis of a Chiral Organic Compound, J. Am. Chem. Soc. 121 (1999) 11235-11236.

[38] R.M. Hazen, T.R. Filley, G.A. Goodfriend, Selective adsorption of L- and D-amino acids on calcite: Implications for biochemical homochirality, Proc. Natl. Acad. Sci. U.S.A. 98 (2001) 5487-5490. 
[39] C.A. Orme, A. Noy, A. Wierzbicki, M.T. McBride, M. Grantham, H.H. Teng, P.M. Dove, J.J. DeYoreo, Formation of chiral morphologies through selective binding of amino acids to calcite surface steps, Nature 411 (2001) 775-779.

[40] C. Viedma, Chiral symmetry breaking during crystallization: Complete chiral purity induced by nonlinear autocatalysis and recycling, Phys. Rev. Lett. 94 (2005) 065504.

[41] C. Viedma, J.M. McBride, B. Kahr, P. Cintas, Enantiomer-specific oriented attachment: Formation of macroscopic homochiral crystal aggregates from a racemic system, Angew. Chem. Int. Ed. 52 (2013) $10545-10548$.

[42] D.T. McLaughlin, T.P.T. Nguyen, L. Mengnjo, C. Bian, Y.H. Leung, E. Goodfellow, P. Ramrup, S. Woo, L.A. Cuccia, Viedma ripening of conglomerate crystals of achiral molecules monitored using solid-state circular dichroism Cryst. Growth Des. 14 (2014) 1067-1076.

[43] C. Viedma, J.E. Ortiz, T. de Torres, T. Izumi, D.G. Blackmond, Evolution of solid phase homochirality for a proteinogenic amino acid, J. Am. Chem. Soc. 130 (2008) 1527415275.

995 [44] L. Spix, H. Meekes, R.H. Blaauw, W.J.P. van Enckevort, E. Vlieg, Complete deracemization of proteinogenic glutamic acid using Viedma ripening on a metastable conglomerate, Cryst. Growth Des. 12 (2012) 5796-5799.

[45] J.R. Cronin, S. Pizzarello, Enantiomeric excesses in meteoritic amino acids, Science 275 (1997) 951-955.

1000 [46] D.P. Glavin, J.P. Dworkin, Enrichment of the amino acid L-isovaline by aqueous alteration on CI and CM meteorite parent bodies, Proc. Natl. Acad. Sci. U.S.A. 106 (2009) 5487-5492.

[47] G. Cooper, A.C. Rios, Enantiomer excesses of rare and common sugar derivatives in carbonaceous meteorites, Proc. Natl. Acad. Sci. U.S.A. 113 (2016) E3322-E3331.

1005

[48] Irvine, The composition of interstellar molecular clouds, Space Sci. Rev. 90 (1999) 203218

[49] E. Herbst, E. F. van Dishoeck, Complex organic interstellar molecules, Annu. Rev. Astron. Astrophys. 47 (2009) 427-480.

1010 [51] B.A. McGuire, P.B. Carroll, R.A. Loomis, I.A. Finneran, P.R. Jewell, A.J. Remijan, G.A. Blake, Discovery of the interstellar chiral molecule propylene oxide $\left(\mathrm{CH}_{3} \mathrm{CHCH}_{2} \mathrm{O}\right)$ Science 352 (2016) 1449-1452.

[52] J.M. Greenberg, J.S. Gillette, G.M. Muñoz Caro, T.B. Mahajan, R.N. Zare, A. Li, W.A. Schutte, M. de Groot, C. Mendoza-Gómez, Ultraviolet photoprocessing of interstellar

1015 dust mantles as a source of polycyclic aromatic hydrocarbons and other conjugated molecules, Astrophys. J. 531 (2000) L71-L73.

[53] W.A. Schutte, Production of organic molecules in interstellar ices, Adv. Space Res. 30 (2002) 1409-1417.

[54] M.P. Bernstein, L.J. Allamandola, S.A. Sandford, Complex organics in laboratory simulation of interstellar/cometary ices, Adv. Space Res. 19 (1997) 991-998.

[55] C. Meinert, I. Myrgorodska, P. de Marcellus, T. Buhse, L. Nahon, S.V. Hoffmann, L. Le Sergeant d'Hendecourt, U.J. Meierhenrich, Ribose and related sugars from ultraviolet irradiation of interstellar ice analogs, Science 352 (2016) 208-212.

[56] P. de Marcellus, C. Meinert, I. Myrgorodska, L. Nahon, T. Buhse, L. Le Sergeant d'Hendecourta, U.J. Meierhenrich, Aldehydes and sugars from evolved precometary ice analogs: Importance of ices in astrochemical and prebiotic evolution, Proc. Natl. Acad. Sci. U.S.A. 112 (2015) 965-970.

[57] J. Crovisier, D. Bockelée-Morvan, Remote observation of the composition of cometary volatiles. Space Sci. Rev. 90 (1999) 19-32. 
1030 [58] D. Bockelée-Morvan, D.C. Lis, J.E. Wink, D. Despois, J. Crovisier, R. Bachiller, D.J. Benford, N. Biver, P. Colom, J.K. Davies, E. Gérard, B. Germain, M. Houde, D. Mehringer, R. Moreno, G. Paubert, T.G. Phillips, H. Rauer, New molecules found in comet C/1995 O1 (Hale-Bopp). Investigating the link between cometary and interstellar material. Astron. Astrophys. 353 (2000) 1101-1114.

1035 [59] N. Biver, D. Bockelée-Morvan, R. Moreno, J. Crovisier, P. Colom, D.C. Lis, A. Sandqvist, J. Boissier, D. Despois, S.N. Milam, Ethyl alcohol and sugar in comet C/2014 Q2 (Lovejoy), Sci. Adv. 1 (2015) e1500863.

[60] L.D. Barron, True and false chirality and absolute asymmetric synthesis, J. Am. Chem. Soc. 108 (1986) 5539-5542.

1040 [61] E. Rubenstein, W.A. Bonner, H.P. Noyes, G.S. Brown, Supernovae and life, Nature 306 (1983) 118.

[62] W.A. Bonner, The origin and amplification of biomolecular chirality, Org. Life Evol. Biosph. 21 (1991) 59-111.

[63] J. Bailey 2001, Astronomical sources of circularly polarized light and the origin of homochirality, Org. Life Evol. Biosph. 31 (2001) 167-183

[64] J. Bailey, A. Chrysostomou, J. H. Hough, T.M. Gledhill, A. McCall, S. Clark, F. Ménard, M. Tamura, Circular polarization in star-formation regions: Implications for biomolecular homochirality, Science 281 (1998) 672-674.

[65] T. Fukue, M. Tamura, R. Kandori, N. Kusakabe, J.H. Hough, P.W. Lucas, J. Bailey, D.C.B Whittet, Y. Nakajima, J. Hashimoto, T. Nagata, Near-Infrared Circular Polarimetry and Correlation Diagrams in the Orion Becklin-Neugebauer/Kleinman-Low Region: Contribution of Dichroic Extinction, Astrophys. J. 692 (2009) L88-L91.

[66] T. Fukue, M. Tamura, R. Kandori, N. Kusakabe, J.H. Hough, J. Bailey, D.C.B Whittet, P.W. Lucas, Y. Nakajima, J. Hashimoto, Extended high circular polarization in the Orion massive star forming region: Implications for the origin of homochirality in the solar system, Orig. Life Evol. Biosph. 40 (2010) 335-346.

[67] J. Kwon, M. Tamura, P.W. Lucas, J. Hashimoto, N. Kusakabe, R. Kandori, Y. Nakajima, T. Nagayama, T. Nagata, J.H. Hough, Near-infrared circular polarization images of NGC 6334-V, Astrophys. J. Lett. 765 (2013) L6.

1060 [68] T.M. Gledhill, A. McCall, Circular polarization by scattering from spheroidal dust grains, Mon. Not. R. Astron. Soc. 314 (2000) 123-137.

[69] J.J. Hester, S.J. Desch, K.R. Healy, L.A. Leshin, The Cradle of the Solar System, Science 304 (2004) 16-17.

1065 Debris from a Nearby Supernova in the Early Solar System?, Astrophys. J. 639 (2006) L87-L90.

[71] H. Rau in Chiral Photochemistry (Eds.: Y. Inoue, V. Ramamurthy), Marcel Dekker, New York, 2004, pp. 1- 44.

[72] O. Buchardt, Photochemistry with circularly polarized light, Angew. Chem. Int. Ed. 13 (1974) 179-185.

[73] Y. Inoue, Asymmetric photochemical reactions in solution, Chem. Rev. 92 (1994) 741770.

[74] P.A. Snyder, P.M. Vipond, W.C. Johnson Jr. Circular dichroism of the alkyl amino acids in the vacuum ultraviolet, Biopolymers 12 (1973) 975-992.

1075 [75] A.C. Evans, C. Meinert, J.H. Bredehöft, C. Giri, N.C. Jones, S.V. Hoffmann, U.J. Meierhenrich, Anisotropy spectra for enantiomeric differentiation of biomolecular building blocks, Top Curr. Chem. 341(2013) 271-299. 
[76] U.J. Meierhenrich, J.-J. Filippi, C. Meinert, J.H. Bredehöft, J. Takahashi, L. Nahon, N.C. Jones, S.V. Hoffmann, Circular dichroism of amino acids in the vacuum-ultraviolet region, Angew. Chem. Int. Ed. 49 (2010) 7799 -7802.

[77] M. Tanaka, K. Yagi-Watanabe, F. Kaneko, K. Nakagawa, Chiroptical study of r-aliphatic amino acid films in the vacuum ultraviolet region, J. Phys. Chem. A 114 (2010) 1192811932.

[78] F. Kaneko, K. Yagi-Watanabe, M. Tanaka, K. Nakagawa, Natural circular dichroism spectra of alanine and valine films in vacuum ultraviolet region, J. Phys. Soc. Jpn. 78 (2009) 013001.

[79] T. Yamada, K. Yagi-Watanabe, M. Tanaka, F. Kaneko, T. Kitada, Y. Ohta, K. Nakagawa, Vacuum ultraviolet circular dichroism spectroscopy using an ac-modulated polarizing undulator. Rev. Sci. Instrum. 76 (2005) 093103.

1090 [80] H. Onuki, Elliptically polarized synchrotron radiation source with crossed and retarded magnetic fields, Nucl. Instrum. Methods Phys. Res. A 246 (1986) 94-98.

[81] T. Hara, K. Shirasawa, M. Takeuchi, T. Seike, Y. Saito, T. Muro, H. Kitamura, Helicity switching of circularly polarized undulator radiation by local orbit bumps, Nucl. Instrum. Methods Phys. Res. A 498 (2003) 496-502.

1095 [82] Y. Izumi, M. Tanabe, A. Imazu, A. Mimoto, M. Tanaka, A. Agui, T. Muro, K. Nakagawa, Characteristic oxygen K-edge circular dichroism spectra of amino acid films by improved measurement technique, J. Chem. Phys. 138 (2013) 074305.

[83] J.H. Bredehöft, N.C. Jones, C. Meinert, A.C. Evans, S.V. Hoffmann, U.J. Meierhenrich, Understanding photochirogenesis: Solvent effects on circular dichroism and anisotropy

$1100 \quad$ spectroscopy, Chirality 26 (2014) 373-378.

[84] W. Kuhn, The physical significance of optical rotary power, Trans. Faraday Soc. 26 (1930) 293-308.

[85] C. Meinert, J.H. Bredehöft, J.-J. Filippi, Y. Baraud, L. Nahon, F. Wien, N.C. Jones, S.V. Hoffmann, U.J. Meierhenrich, Anisotropy spectra of amino acids, Angew. Chem. Int. Ed.

$1105 \quad 51(2012) 4484-4487$.

[86] A. Nakamura, H .Nishino, Y. Inoue, Synchronous enantiomeric enrichment of both reactant and product by absolute asymmetric synthesis using circularly polarized light.

Part 2. Verification of the validity of assuming first-order kinetics upon deriving the equation for the relationship between conversion and enantiomeric excess. J. Chem .Soc.

$1110 \quad$ Perkin Trans. 2 (2001) 1701-1705.

[87] W. Kuhn, E. Braun, Photochemische Erzeugung optisch aktiver Stoffe, Naturwissenschaften 17 (1929) 227-228.

[88] G. Balavoine, A. Moradpour, H.B. Kagan, Preparation of Chiral Compounds with High Optical Purity by Irradiation with Circularly Polarized Light, a Model Reaction for the

1115 Prebiotic Generation of Optical Activity, J. Am. Chem. Soc. 96 (1974) 5152-5158.

[89] Y. Inoue, H. Tsuneishi, T. Hakushi, K. Yagi, K. Awazu, H. Onuki, First absolute asymmetric synthesis with circularly polarized synchrotron radiation in the vacuum ultraviolet region: direct photoderacemization of $(E)$-cyclooctene, Chem. Commun. (1996) 2627-2728.

1120 [90] W. Bonner, Enantiomeric markers in the quantitative gas chromatographic analysis of optical isomers. Application to the estimation of amino acid degradation, J. Chromatogr. Sci. 11 (1973) 101-104.

[91] B. Norden, Was photoresolution of amino acids the origin of optical activity in life?, Nature 266 (1977) 567-568.

1125 [92] J.J. Flores, W.A. Banner, G.A. Massey, Asymmetric photolysis of (RS)-leucine with circularly polarized ultraviolet light, J. Am. Chem. Soc. 99 (1977) 3622-3625. 
[93] H. Nishino, A. Kosaka, G.A. Hembury, H. Shitomi, H. Onuki, Y. Inoue, Mechanism of $\mathrm{pH}$-dependent photolysis of aliphatic amino acids and enantiomeric enrichment of racemic leucine by circularly polarized light, Org. Lett. 3 (2001) 921-924.

1130 [94] L.J Mittal, J.P Mittal, E. Hayon, Photo-induced decarboxylation of aliphatic acids and esters in solution. Dependence upon state of protonation of the carboxyl group, J. Phys. Chem. 77 (1973) 1482-1487.

[95] H. Nishino, A. Kosaka, G.A. Hembury, K. Matsushima, Y. Inoue, The pH dependence of the anisotropy factors of essential amino acids, J. Chem. Soc. Perkin Trans. 2 (2002)

1135 582-590.

[96] U.J. Meierhenrich, L. Nahon, C. Alcaraz, J.H. Bredehöft, S.V. Hoffmann, B. Barbier, A. Brack, Asymmetric vacuum UV photolysis of the amino acid leucine in the solid state, Angew. Chem. Int. Ed. 44 (2005) 5630-5634.

[97] U.J. Meierhenrich, J.-J. Filippi, C. Meinert, S.V. Hoffmann, J.H. Bredehöft, L. Nahon, Photolysis of rac-leucine with circularly polarized synchrotron radiation, Chem. Biodiversity 7 (2010) 1651-1659

[98] C. Meinert, S.V. Hoffmann, P. Cassam-Chenaï, A.C. Evans, C. Giri, L. Nahon, U.J. Meierhenrich, Photonenergy-controlled symmetry breaking with circularly polarized light, Angew. Chem. 126 (2014) 214-218.

1145 [99] C. Meinert, P. Cassam-Chenaï, N.C. Jones, L. Nahon, S.V. Hoffmann, U.J. Meierhenrich, Anisotropy-guided enantiomeric enhancement in alanine using far-UV circularly polarized light, Orig. Life Evol. Biosph. 45 (2015) 149-161.

[100] M. Tia, B.C. de Miranda, S. Daly, F. Gaie-Levrel, G.A. Garcia, I. Powis, L. Nahon, Chiral asymmetry in the photoionization of gas-phase amino-acid alanine at Lyman- $\alpha$

1150 radiation wavelength, J. Phys. Chem. Lett. 4 (2013) 2698-2704.

[101] M. Tia, B. Cunha de Miranda, S. Daly, F. Gaie-Levrel, G.A. Garcia, L. Nahon, I. Powis, VUV photodynamics and chiral asymmetry in the photoionization of gas phase alanine enantiomers, J. Phys. Chem. A 118 (2014) 2765-2779.

[102] L. Nahon, G.A. Garcia, I. Powis, Valence shell one-photon photoelectron circular dichroism in chiral systems. J. Elec. Spec. Rel. Phen. 204 (2015) 322-334.

[103] J.M. Greenberg, Cosmic dust and our origins, Surf. Sci. 500 (2002) 793-822.

[104] E. Dartois, The ice survey opportunity of ISO, Space Sci. Rev.119 (2005) 293-310.

[105] M.P. Bernstein, J.P. Dworkin, S.A. Sandford, G.W. Cooper, L.J. Allamandola, Racemic amino acids from the ultraviolet photolysis of interstellar ice analogues, Nature 416

1160 (2002) 401-403.

[106] G.M. Muñoz Caro, U.J. Meierhenrich, W.A. Schutte, B. Barbier, A. Arcones Segovia, H. Rosenbauer, W.H.-P. Thiemann, A. Brack, J.M. Greenberg, Nature 416 (2002) 403406.

1165

[107] M. Nuevo, G. Auger, D. Blanot, L. d'Hendecourt, A detailed study of the amino acids produced from the vacuum UV irradiation of interstellar ice analogs, Orig. Life Evol. Biosph. 38 (2008) 37-56.

[108] U.J. Meierhenrich, G.M. Muñoz Caro, J.H. Bredehöft, E.K. Jessberger, W.H.P. Thiemann, Identification of diamino acids in the Murchison meteorite. Proc. Natl. Acad. Sci. USA. 101 (2004) 9182-9186.

1170 [109] K. Kobayashi,T, Kasamatsu, T. Kaneko, J. Koike, T. Oshima, T. Saito, T. Yamamotot, H. Yanagawa, Formation of amino acid precursors in cometary ice environments by cosmic radiation. Adv. Space Res. 16 (1995) 21-26.

[110] Y. Takano, A. Ohashi, T. Kaneko, K. Kobayashi, Abiotic synthesis of high-molecularweight organics from an inorganic gas mixture of carbon monoxide, ammonia, and water by $3 \mathrm{MeV}$ proton irradiation, Appl. Phys. Lett. 84 (2004) 1410-1412. 
[111] Y. Takano, H. Masuda, T. Kaneko, K. Kobayashi, Formation of amino acids from possible interstellar media by $\gamma$-rays and UV Irradiation, Chem. Lett. 31 (2002) 986-987.

[112] K. Kobayashi, Y. Takano, H. Masuda, H. Tonishi, T. Kaneko, H. Hashimoto, T. Saito, Possible cometary organic compounds as sources of planetary biospheres, Adv. Space

$1180 \quad$ Res. 33 (2004) 1277-1281.

[113] P.D. Holtom, C.J. Bennett, Y. Osamura, N.J. Mason, R.I. Kaiser, A combined experimental and theoretical study on the formation of the amino acid glycine $\left(\mathrm{NH}_{2} \mathrm{CH}_{2} \mathrm{COOH}\right)$ and its isomer $\left(\mathrm{CH}_{3} \mathrm{NHCOOH}\right)$ in extraterrestrial ices, Astrophys. J. 626 (2005) 940-952.

1185 [114] Y. Oba, Y. Takano, N. Watanabe, A. Kouchi, Deuterium Fractionation during amino acid formation by photolysis of interstellar ice analogs containing deuterated methanol, Astrophys. J. Lett. 827 (2016) L18.

[115] Y. Oba, Y. Takano, H. Naraoka, A. Kouchi, N. Watanabe, Deuterium fractionation upon the formation of hexamethylenetetramines through photochemical reactions of interstellar ice analogs containing deuterated methanol isotopologues, Astrophys. J. 849 (2017) 122.

[116] M. Nuevo, U.J. Meierhenrich, G.M. Muñoz Caro1, E. Dartois, L. d'Hendecourt, D. Deboffle1, G. Auger, D. Blanot, J.-H. Bredehöft, L. Nahon, The effects of circularly polarized light on amino acid enantiomers produced by the UV irradiation of interstellar

1195 ice analogs, Astron. Astrophys. 457 (2006) 741-751.

[117] M. Nuevo, U.J. Meierhenrich, L. d'Hendecourt, G.M. Muñoz Caro, E. Dartois, D. Deboffle, W.H.-P. Thiemann, J.-H. Bredehöft, L. Nahon, Enantiomeric separation of complex organic molecules produced from irradiation of interstellar/circumstellar ice analogs, Adv. Space Res. 39 (2007) 400-404.

1200 [118] P. de Marcellus, C. Meinert, M. Nuevo, J.-J. Filippi, G. Danger, D. Deboffle, L. Nahon, L. Le Sergeant d'Hendecourt, U.J. Meierhenrich, Non-racemic amino acid production by ultraviolet irradiation of achiral interstellar ice analogs with circularly polarized light, Astrophys. J. Lett. 727 (2011) L27.

[119] P. Modica, C. Meinert, P. de Marcellus, L. Nahon, U.J. Meierhenrich, L. Le Sergeant d'Hendecourt, Enantiomeric excesses induced in amino acids by ultraviolet circularly polarized light irradiation of extraterrestrial ice analogues: A possible source of asymmetry for prebiotic chemistry, Astrophys. J. 788 (2014) 79.

[120] M. Tanaka, K. Yagi-Watanabe, F. Kaneko, K. Nakagawa, First observation of natural circular dichroism spectra in the extreme ultraviolet region using a polarizing undulatorbased optical system and its polarization characteristics, J. Synchrotron Rad. 16 (2009) 455-462.

[121] Y. Takano, J. Takahashi, T. Kaneko, K. Marumo, K. Kobayashi, Asymmetric synthesis of amino acid precursors in interstellar complex organics by circularly polarized light, Earth Planet. Sci. Lett. 254 (2007) 106-114.

1215 [122] A.N. Krot, K. Keil, E.R.D. Scott, C.A. Goodrich, M.K. Weisberg, 1.1 Classification of meteorites and their genetic relationships, Treatise on Geochemistry 2nd Edition, 1 (2014) 1-63.

[123] C.M.O’D. Alexander, R. Bowden, M.L. Fogel, K.T. Howard, C.D.K. Herd, L.R. Nittler, The provenances of asteroids, and their contributions to the volatile inventories of the $1220 \quad$ terrestrial planets, Science 337 (2012) 721-723.

[124] C.M.O'D. Alexander, G.D. Cody, B.T. De Gregorio, L.R. Nittler, R.M. Stroud, The nature, origin and modification of insoluble organic matter in chondrites, the major source of Earth's C and N, Chemie der Erde 77 (2017) 227-256. 
[125] K. Kvenvolden, J. Lawless, K. Pering, E. Peterson, J. Flores, C. Ponnamperuma, I.R. Kaplan, C. Moor, Evidence for Extraterrestrial amino-acids and hydrocarbons in the Murchison meteorite, Nature 228 (1970) 923-926.

[126] J.R. Cronin, W.E. Gandy, S. Pizzarello, Amino acids of the Murchison meteorite: I. Six carbon acyclic primary $\alpha$-amino alkanoic acids, J. Mol. Evol. 17 (1981) 265-272.

[127] J.R. Cronin, S. Pizzarello, G.U. Yuen, Amino acids of the Murchison meteorite: II. Five carbon acyclic primary $\beta$-, $\gamma$ - and $\delta$-amino alkanoic acids, Geochim. Cosmochim. Acta 49 (1985) 2259-2265.

[128] J.R. Cronin, S. Pizzarello, Amino acids of the Murchison meteorite. III. Seven carbon acyclic primary a-amino alkanoic acids, Geochim. Cosmochim. Acta 50 (1986) 24192427.

1235 [129] T. Koga, H. Naraoka, A new family of extraterrestrial amino acids in the Murchison meteorite, Nature Sci. Rep. 7 (2017) 636.

[130] A.S. Burton, J.C. Stern, J.E. Elsila, D.P. Glavin, J.P. Dworkin, Understanding prebiotic chemistry through the analysis of extraterrestrial amino acids and nucleobases in meteorites, Chem. Soc. Rev. 41 (2012) 5459-5472.

1240 [131] D.P. Glavin, M.P. Callahan, J.P. Dworkin, J.E. Elsila, The effects of parent body processes on amino acids in carbonaceous chondrites, Meteorit. Planet. Sci. 45 (2011) $1948-1972$.

[132] A.S. Burton, J.E. Elsila, M.P. Callahan, M.G. Martini, D.P. Glavin, N.M. Johnson, J.P. Dworkin, A propensity for $n$ - $\omega$-amino acids in thermally altered Antarctic meteorites,

1245 Meteorit. Planet. Sci. 47 (2012) 374-386.

[133] H.-S. Chan, Z. Martins, M. Sephton, Amino acid analyses of type 3 chondrites Colony, Ornans, Chainpur, and Bishunpur, Meteorit. Planet. Sci. 47 (2012) 1502-1516.

[134] A.S. Burton, H. McLain, D.P. Glavin, J.E. Elsila, J. Davidson, K.E. Miller, A.V. Andronikov, D. Lauretta, J.P. Dworkin, Amino acid analyses of R and CK chondrites,

$1250 \quad$ Meteorit. Planet. Sci. 50 (2015) 470-482.

[135] Z. Martins, C.M.O’D. Alexander, G.E. Orzechowska, M.L. Fogel, P. Ehrenfreund, Indigenous amino acids in primitive CR meteorites, Meteorit. Planet. Sci. 42 (2007) 2125-2136.

[136] O. Botta, Z. Martins, P. Ehrenfreund, Amino acids in Antarctic CM1 meteorites and their relationship to other carbonaceous chondrites, Meteorit. Planet. Sci. 42 (2007) 8192.

[137] Z. Martins, P. Modica, B. Zanda, L. le Sergeant d'Hendecourt, The amino acid and hydrocarbon contents of the Paris meteorite: Insights into the most primitive CM chondrite, Meteorit. Planet. Sci. 50 (2015) 926-943.

1260 [138] Q. Chan, Y. Chikaraishi, Y. Takano, N.O. Ogawa, N. Ohkouchi, Amino acid compositions in heated carbonaceous chondrites and their compound-specific nitrogen isotopic ratios. Earth, Planets Space 68 (2016) 7. doi:10.1186/s40623-40016-4038240628.

[139] Z. Martins, M.A. Sephton, Extraterrestrial amino acids, in: A.B. Hughes (Ed.), Amino Acids, Peptides and Proteins in Organic Chemistry. Vol.1 - Origins and Synthesis of Amino Acids, Wiley-VCH publishers, Germany, 2009, pp. 3-42.

[140] J.E. Elsila, S.B. Charnley, A.S. Burton, D.P. Glavin, J.P. Dworkin, Compound-specific carbon, nitrogen, and hydrogen isotopic ratios for amino acids in CM and CR chondrites and their use in evaluating potential formation pathways, Meteorit. Planet. Sci. 47 (2012) $1517-1536$. 
[141] J. Crovisier, D. Bockelée-Morvan, P. Colom, N.Biver, D.Despois, D.C. Lis, the Team for Target-of-Opportunity Radio Observations of Comets. The composition of ices in comet C/1995 O1 (Hale-Bopp) from radio spectroscopy: Further results and upper limits on undetected species. Astron. Astrophys. 418 (2004) 1141-1157.

1275 [142] D. Brownlee, The Stardust Mission: Analyzing samples from the edge of the Solar System, Annu. Rev. Earth Planet. Sci. 42 (2014)179-205.

[143] J.E. Elsila, D.P. Glavin, J.P. Dworkin, Cometary glycine detected in samples returned by Stardust, Meteorit. Planet. Sci. 44 (2009) 1323-1330.

[144] F. Goesmann, H. Rosenbauer, J.H. Bredehöft, M.Cabane, P. Ehrenfreund, T. Gautier, C. Giri, H. Krüger, L. Le Roy, A.J. MacDermott, S. McKenna-Lawler, U.J. Meierhenrich, G.M. Munoz Caro, F. Raulin, R. Roll, A. Steele, H. Steininger, R. Sternberg, C. Szopa, W. Thiemann, S. Ulamec, Organic compounds on comet 67P/Churyumov-Gerasimenko revealed by COSAC mass spectrometry, Science 349 (2015) aab0689.

1285 [145] S. Ulamec, C. Fantinati, M. Maibaum, K. Geurts, J. Biele, S. Jansen, O. Küchemann, B. Cozzoni, F. Finke, V. Lommatsch, A. Moussi-Soffys, C. Delmas, L. O'Rourke, Rosetta Lander - Landing and operations on comet 67P/Churyumov-Gerasimenko, Acta Astron. 125 (2016) 80-91.

[146] K. Altwegg, H. Balsiger, A. Bar-Nun, J.-J. Berthelier, A. Bieler, P. Bochsler, C. Briois, U. Calmonte, M.R. Combi, H. Cottin, J. De Keyser, F. Dhooghe, B. Fiethe, S.A. Fuselier, S. Gasc, T.I. Gombosi, K.C. Hansen, M. Haessig, A. Jäckel, E. Kopp, A. Korth, L. Le Roy, U. Mall, B. Marty, O. Mousis, T. Owen, H. Rème, M. Rubin, T. Sémon, C.-Y. Tzou, J. H. Waite, P. Wurz, Prebiotic chemicals - amino acid and phosphorus - in the coma of comet 67P/Churyumov-Gerasimenko, Sci. Adv. 2 (2016) e1600285

1295 [147] K.A. Kvenvolden, J.G. Lawless, C. Ponnamperuma, Nonprotein amino acids in the Murchison meteorite, Proc. Natl. Acad. Sci. U.S.A. 68 (1971) 486-490.

[148] G.E. Pollock, C.-N. Cheng, S.E. Cronin, K.A. Kvenvolden, Stereoisomers of isovaline in the Murchison meteorites, Geochim. Cosmochim. Acta 39 (1975) 1571-1573.

$1300 \quad$ indigenous to the Murray meteorite, Science 173 (1971) 626-627.

[150] M.H. Engel, B. Nagy, Distribution and enantiomeric composition of amino acids in the Murchison meteorite, Nature 296 (1982) 837-840.

[151] S. Pizzarello, J.R. Cronin, Non-racemic amino acids in the Murray and Murchison meteorites, Geochim. Cosmochim. Acta 64 (2000) 329-338.

1305 [152] J.L. Bada, J.R. Cronin, M.-S. Ho, K.A. Kvenvolden, J.G. Lawless, S.L. Miller, J. Oro, S. Steinberg, On the reported optical activity of amino acids in the Murchison meteorite, Nature 301 (1983) 494-496.

[153] J.R. Cronin, S. Pizzarello, Enantiomeric excesses in meteoritic amino acids, Science 275 (1997) 951-955.

1310 [154] S. Pizzarello, M. Zolensky, K.A. Turk, Nonracemic isovaline in the Murchison meteorite: Chiral distribution and mineral association, Geochim. Cosmochim. Acta 67 (2000) 1589-1595.

[155] D.P. Glavin, J.P. Dworkin, Enrichment of the amino acid L-isovaline by aqueous alteration on CI and CM meteorite parent bodies, Proc. Natl. Acad. Sci. U.S.A. 106 (2009) 5487-5492.

[156] D.P. Glavin, M.P. Callahan, J.P. Dworkin, J.E. Elsila, The effects of parent body processes on amino acids in carbonaceous chondrites, Meteorit. Planet. Sci. 45 (2011) 1948-1972.

[157] N. Ohkouchi, Y. Chikaraishi, H. Close, B. Fry, T. Larsen, D.J. Madigan, M.D. McCarthy, K.W. McMahon, T. Nagata, Y.I. Naito, N.O. Ogawa, B.N. Popp, S.A. Steffan, 
Y. Takano, I. Tayasu, A. Wyatt, Y.T. Yamaguchi, Y. Yokoyama, Advances in the application of amino acid nitrogen isotopic analysis in ecological and biogeochemical studies, Org. Geochem. 113 (2017) 150-174.

[158] I. Myrgorodska, C. Meinert, Z. Martins, L. le Sergeant d'Hendecourt, U. J.

Meierhenrich, Quantitative enantioseparation of amino acids by comprehensive twodimensional gas chromatography applied to non-terrestrial samples, J. Chromatogr. A 1433 (2016) 131-136.

[159] C. Meinert, U.J. Meierhenrich, A new dimension in separation science: comprehensive two-dimensional gas chromatography, Angew. Chem. Int. Ed. 51 (2012) 10460-10470.

1330 [160] K. Hamase, Y. Nakauchi, Y. Miyoshi, R. Koga, N. Kusano, H. Onigahara, H. Naraoka, H. Mita, Y. Kadota, Y. Nishino, M. Mita, W. Lindner, Chromatogr. 35 (2014) 103-110.

[161] K. Hamase, A. Morikawa, T. Ohgusu, W. Lindner, K. Zaitsu, Comprehensive analysis of branched aliphatic d-amino acids in mammals using an integrated multi-loop twodimensional column-switching high-performance liquid chromatographic system

1335 combining reversed-phase and enantioselective columns, J. Chromatogr. A 1143 (2007) $105-111$.

[162] T.N. Tingle, J.A. Tyburczy, T.J. Ahrens, C.H. Becker The fate of organic matter during planetary accretion: preliminary studies of the organic chemistry of experimentally shocked Murchison meteorite. Orig. Life Evol. Biosph 21 (1992) 385-397.

1340 [163] Y.Sekine, K. Kodama, T. Kobayashi, S. Obata, Y. Chang, N.O. Ogawa, Y. Takano, N. Ohkouchi, K. Saiki, T. Sekine, An experimental study on impact-induced alterations of planetary organic simulants. Meteorit. Planet. Sci. (2017) in revision.

[164] E. Peterson, F. Horz, S. Chang, Modification of amino acids at shock pressures of 3.5 to $32 \mathrm{GPa}$. Geochim. Cosmochim. Acta 61 (1997) 3937-3950.

1345 [165] H. Sugahara, K. Mimura, K. Shock-induced pyrolysis of amino acids at ultra high pressures ranged from 3.2 to 35.3 GPa. J. Anal. Appl. Pyrolysis 108 (2015) 170-175.

[166] S.P. Marsh, LASL Shock Hugoniot Data. (1980) University of California Press, Berkeley.

[167] S.T. Stewart, T.J. Ahrens, Shock properties of $\mathrm{H}_{2} \mathrm{O}$ ice. J. Geophys. Res. 110 (2005) E03005.

[168] C.F. Chyba, Impact delivery and erosion of planetary oceans in the early inner Solar System, Nature 343 (1990) 129-133.

[169] D.W. Hughes, I.P. Williams, The velocity distributions of periodic comets and stream meteoroids. Mon. Not. R. Astron. Soc. 315 (2000.)629-634.

1355 [170] H. Sugahara, K. Mimura, Peptide synthesis triggered by comet impacts: A possible method for peptide delivery to the early Earth and icy satellites. Icarus 257 (2015) 103112.

[171] Y. Furukawa, A. Takase, T. Sekine, T. Kakegawa, T. Kobayashi, Racemization of valine by impact-induced heating, Orig. Life Evol. Biosph. (2017) doi: 10.1007/s110841360 017-9539-0

[172] H. Sugahara, K. Mimura, Glycine oligomerization up to triglycine by shock experiments simulating comet impacts. Geochem. J. 48 (2014) 51-62.

[173] Z. Martins, M.C. Price, N. Goldman, M.A. Sephton, M. Burchell, Shock synthesis of amino acids from impacting cometary and icy planet surface analogues. Nature Geosci. 6 1365 (2013) 1045-1049.

[174] N. Goldman, E.J. Reed, L.E. Fried, I.-F.W Kuo, A. Maiti, Synthesis of glycinecontaining complexes in impacts of comets on early Earth. Nature Chem. 2 (2010) 949854.

[175] K. Soai, T. Shibata, H. Morioka, K. Choji, Asymmetric autocatalysis and amplification of enantiomeric excess of a chiral molecule, Nature 378 (1995) 767-768. 
[176] T. Kawasaki, M. Sato, S. Ishiguro, T.Saito, Y. Morishita, I. Sato, H. Nishino, Y. Inoue, K. Soai, Enantioselective synthesis of near enantiopure compound by asymmetric autocatalysis triggered by asymmetric photolysis with circularly polarized light, J. Am. Chem. Soc. 127 (2005) 3274-3275.

1375 [177] T. Kawasaki, M. Shimizu, D. Nishiyama, M. Ito, H. Ozawa, K. Soai, Asymmetric autocatalysis induced by meteoritic amino acids with hydrogen isotope chirality, Chem. Commun. (2009) 4396-4398.

[178] T. Kawasaki, Y. Matsumura, T. Tsutsumi, K. Suzuki, M. Ito, K. Soai, Asymmetric autocatalysis triggered by carbon isotope $\left({ }^{13} \mathrm{C} /{ }^{12} \mathrm{C}\right)$ Chirality, Science 324 (2009) 492$1380 \quad 495$.

[179] W.L. Noorduin, A.A.C. Bode1, M. van der Meijden, H. Meekes, A.F. van Etteger, W.J.P. van Enckevort, P.C.M. Christianen, B. Kaptein, R.M. Kellogg, T. Rasing, E. Vlieg, Complete chiral symmetry breaking of an amino acid derivative directed by circularly polarized light, Nature Chem. 1 (2009) 729-732.

1385 [180] M. Levine, C.S. Kenesky, D. Mazori, R. Breslow, Enantioselective synthesis and enantiomeric amplification of amino acids under prebiotic conditions, Org. Lett. 10 (2008) 2433-2436.

[181] A. Tsuchiyama, M. Uesugi, T. Matsushima, T. Michikami, T. Kadono, T. Nakamura, K. Uesugi, T. Nakano, S.A. Sandford, R. Noguchi, T. Matsumoto, J. Matsuno, T.

1390 Nagano, Y. Imai, A. Takeuchi, Y. Suzuki, T. Ogami, J. Katagiri, M. Ebihara, T.R. Ireland, F. Kitajima, K. Nagao, H. Naraoka, T. Noguchi, R. Okazaki, H. Yurimoto, M.E. Zolensky, T. Mukai, M. Abe, T. Yada, A. Fujimura, M. Yoshikawa, J. Kawaguchi, Three-dimensional structure of Hayabusa samples: Origin and evolution of Itokawa regolith, Science 333 (2011) 1125-1128.

1395 [182] K. Nagao, R. Okazaki, T. Nakamura, Y.N. Miura, T. Osawa, K. Bajo, S. Matsuda, M. Ebihara, T.R. Ireland, F. Kitajima, H. Naraoka, T. Noguchi, A. Tsuchiyama, H. Yurimoto, M.E. Zolensky, M. Uesugi, K. Shirai, M. Abe, T. Yada, Y. Ishibashi, A. Fujimura, T. Mukai, M. Ueno, T. Okada, M. Yoshikawa, J. Kawaguchi, Irradiation history of Itokawa regolith material deduced from noble gases in the Hayabusa samples,

$1400 \quad$ Science 333 (2011) 1128-1131.

[183] H. Yurimoto, K. Abe, M. Abe, M. Ebihara, A. Fujimura, M. Hashiguchi, K. Hashizume, T.R. Ireland, S. Itoh, J. Katayama, C. Kato, J. Kawaguchi, N. Kawasaki, F. Kitajima, S. Kobayashi, T. Meike, T. Mukai, K. Nagao, T. Nakamura, H. Naraoka, T. Noguchi, R. Okazaki, C. Park, N. Sakamoto, Y. Seto, M. Takei, A. Tsuchiyama, M. Uesugi, S. Wakaki, T. Yada, K. Yamamoto, M. Yoshikawa, M.E. Zolensky, Oxygen isotopic compositions of asteroidal materials returned from Itokawa by the Hayabusa mission, Science 333 (2011) 1116-1119.

[184] T Nakamura, T. Noguchi, M. Tanaka, M.E. Zolensky, M. Kimura, A. Tsuchiyama, A. Nakato, T. Ogami, H. Ishida, M. Uesugi, T. Yada, K. Shirai, A. Fujimura, R. Okazaki, S.A. Sandford, Y. Ishibashi, M. Abe, T. Okada, M. Ueno, T. Mukai, M. Yoshikawa, J. Kawaguchi, Itokawa dust particles: A direct link between S-type asteroids and ordinary chondrites, Science 333 (2011) 1113-1115.

[185] T. Noguchi, T. Nakamura, M. Kimura, M.E. Zolensky, M. Tanaka, T. Hashimoto, M. Konno, A. Nakato, T. Ogami, A. Fujimura, M. Abe, T. Yada, T. Mukai, M. Ueno, T. Okada, K. Shirai, Y. Ishibashi, R. Okazaki, Incipient space weathering observed on the surface of Itokawa dust particles, Science 333 (2011) 1121-1125.

[186] S. Tachibana, M. Abe, M. Arakawa, M. Fujimoto, Y. Iijima, M. Ishiguro, K. Kitazato, N. Kobayashi, N. Namiki, T. Okada, R. Okazaki, H. Sawada, S. Sugita, Y. Takano, S. Tanaka, S. Watanabe, M. Yoshikawa, H. Kuninaka, the Hayabusa2 Project Team, 
Hayabusa2: Scientific importance of samples returned from C-type near-Earth asteroid (162173) $1999 \mathrm{JU}_{3}$, Geochem. J. 48 (2014) 571-587.

[187] S. Watanabe, Y. Tsuda, M. Yoshikawa, S. Tanaka, T. Saiki, S. Nakazawa, Hayabusa2 Mission Overview, Space Sci. Rev. 208 (2017) 3-16.

[188] D.S. Lauretta, S.S. Balram-Knutson, E. Beshore, W.V. Boynton, C. Drouet d'Aubigny, D.N. DellaGiustina, H.L. Enos, D.R. Golish, C.W. Hergenrother, E.S. Howell, C.A. Bennett, E.T. Morton, M.C. Nolan, B. Rizk, H.L. Roper, A.E. Bartels, B.J. Bos, J.P. Dworkin, D.E. Highsmith, D.A. Lorenz, L.F. Lim, R. Mink, M.C. Moreau, J.A. Nuth, D.C. Reuter, A.A. Simon, E.B. Bierhaus, B.H. Bryan, R. Ballouz, O.S. Barnouin, R.P. Binzel, W.F. Bottke, V.E. Hamilton, K.J. Walsh, S.R. Chesley, P.R. Christensen, B.E. Clark, H.C. Connolly, M.K. Crombie, M.G. Daly, J.P. Emery, T.J. McCoy, J.W.

McMahon, D.J. Scheeres, S. Messenger, K. Nakamura-Messenger, K. Righter, S.A. Sandford, OSIRIS-REx: Sample Return from Asteroid (101955) Bennu, Space Sci. Rev. 212 (2017) 925-984.

[189] S.A. Sanford., S. Bajt, S.J. Clemett, G.D. Cody, G. Cooper, B.T. Degregorio, V. de Vera, J.P. Dworkin, J.E. Elsila, G.J. Flynn, D.P. Glavin, A. Lanzirotti, T. Limero, M.P. Martin, C.J. Snead, M.K. Spencer, T. Stephan, A. Westphal, S. Wirick, R.N. Zare, M.E. Zolensky, Assessment and control of organic and other contaminants associated with the Stardust sample from comet 81P/Wild 2, Meteorit. Planet. Sci. 45 (2010) 406-433.

[190] D.P. Glavin, J.P. Dworkin, A. Aubrey, O. Botta, J.H. Doty III, Z. Martins, J.L. Bada, Amino acid analyses of Antarctic CM2 meteorites using liquid chromatography-time of flight-mass spectrometry, Meteorit. Planet. Sci. 41 (2006) 889-902.

[191] T. Yada, A. Fujimura, M. Abe, T. Nakamura, T. Noguchi, R. Okazaki, K. Nagao, Y. Ishibashi, K. Shirai, M.E. Zolensky, S. Sandford, T. Okada, M. Uesughi, Y. Karouji, M. Ogawa, S. Yakane, M. Ueno, T. Mukai, M. Yoshikawa, J. Kawaguchi, Hayabusareturned sample curation in the Planetary Material Sample Curation Facility of JAXA, Meteorit. Planet. Sci. 49 (2014) 135-153.

[192] H. Naraoka, H. Mita, K. Hamase, M. Mita, H. Yabuta, K. Saito, K. Fukushima, F. Kitajima, S.A. Sandford, T. Nakamura, T. Noguchi, R. Okazaki, K. Nagao, M. Ebihara, H. Yurimoto, A. Tsuchiyama, M. Abe, K. Shirai, M. Ueno, T. Yada, Y. Ishibashi, T. Okada, A. Fujimura, T. Mukai, M. Yoshikawa, J. Kawaguchi, Preliminary organic compound analysis of microparticles returned from Asteroid 25143 Itokawa by the Hayabusa mission, Geochem. J. 46 (2012) 46-61.

[193] M. Uesugi, H. Naraoka, M. Ito, H. Yabuta, F. Kitajima, Y. Takano, H. Mita, I. Ohnishi, Y. Kebukawa, T. Yada, Y. Karouji, Y. Ishibashi, T. Okada, M. Abe, Sequential analysis of carbonaceous materials in Hayabusa-returned samples for the determination of their origin, Earth, Planets Space 66 (2014) 102.

[194] H. Yabuta, M. Uesugi, H. Naraoka, M. Ito, A.L.D. Kilcoyne, .A Sandford, F. Kitajima, H. Mita, Y. Takano, T. Yada, Y. Karouji, Y. Ishibashi, T. Okada, M. Abe, X-ray absorption near edge structure spectroscopic study of Hayabusa category 3 carbonaceous 1460 particles, Earth, Planets Space 66 (2014) 156.

[195] H. Naraoka, D. Aoki, K. Fukushima, M. Uesugi, M. Ito, F. Kitajima, H. Mita, H. Yabuta, Y. Takano, T. Yada, Y. Ishibashi, Y. Karouji, T. Okada, M. Abe, ToF-SIMS analysis of carbonaceous particles in the sample catcher of the Hayabusa spacecraft, Earth, Planets Space 67 (2015) 67.

1465 [196] R. Okazaki, H. Sawada, S. Yamanouchi, S. Tachibana, Y.N. Miura, K. Sakamoto, Y. Takano, M. Abe, S. Itoh, K. Yamada, H. Yabuta, C. Okamoto, H. Yano, T. Noguchi, T. Nakamura, K. Nagao, The Hayabusa2 SMP Team, Hayabusa2 sample catcher and container: Metal-seal system for vacuum encapsulation of returned samples with volatiles 
and organic compounds recovered from C-type asteroid Ryugu, Space Sci. Rev. 208 (2016) 107-124.

[197] H. Sawada, R. Okazaki, S. Tachibana, K. Sakamoto, Y. Takano, C. Okamoto, H. Yano, Y. Miura, M. Abe, S. Hasegawa, T. Noguchi, Hayabusa2 SMP Team, Hayabusa2 sampler: Collection of asteroidal surface material, Space Sci. Rev. 208 (2017) 81-106.

[198] H. Sugahara, Y. Takano, Y. Karouji, M. Abe, Hayabusa2 project team, Amino acid analysis of witness coupons collected from IASA curation room for the quality control of Hayabusa2 return sample procedure, The 7th Symposium on Polar Science abstract (2016).

[199] J.P. Dworkin, L.A. Adelman, T. Ajluni, A.V. Andronikov, J.C. Aponte, A.E. Bartels, E. Beshore, E.B. Bierhaus, J.R. Brucato, B.H. Bryan, A.S. Burton, M.P. Callahan, S.L. Castro-Wallace, B.C. Clark, S.J. Clemett, H.C. Connolly Jr., W.E. Cutlip, S.M. Daly, V.E. Elliott, J.E. Elsila, H.L. Enos, D.F. Everett, I.A. Franchi, D.P. Glavin, H.V. Graham, J.E. Hendershot, J.W. Harris, S.L. Hill, A.R. Hildebrand, G.O. Jayne, R.W. Jenkens Jr., K.S. Johnson, J.S. Kirsch, D.S. Lauretta, A.S. Lewis, J.J. Loiacono, C.C. Lorentson, J.R. Marshall, M.G. Martin, L.L. Matthias, H.L. McLain, S.R. Messenger, R.G. Mink, J.L.

Moore, K. Nakamura-Messenger, J.A. Nuth III, C.V. Owens, C.L. Parish, B.D. Perkins, M.S. Pryzby, C.A. Reigle, K.Righter, B. Rizk, J.F. Russell, S.A. Sandford, J.P. Schepis, J. Songer, M.F. Sovinski, S.E. Stahl, K. Thomas-Keprta, J.M. Vellinga, M.S. Walker, OSIRIS-REx contamination control strategy and implementation, Space Sci. Rev. 214 (2018) 19.

1490 [200] R. Hyodo, H. Genda, S. Charnoz, P. Rosenblatt, On the impact origin of Phobos and Deimos. I. Thermodynamic and physical aspects. Astrophys. J. 845 (2017) 125.

[201] J. Kikuchi, S. Suzuki, H. Kato, H. Sawada, M. Otsuki, 3D mapping by active stereo sensor on sampling mission of asteroid surface, Aerospace Conference IEEE (2017) doi: 10.1109/AERO.2017.7943674

[202] J.L. Vago, F. Westall, Pasteur Instrument Teams, Landing Site Selection Working Group, and Other Contributors, Habitability on early Mars and the search for biosignatures with the ExoMars rover, Astrobiol. 17 (2017) 471-510.

[203] W. Goetz, W.B. Brinckerhoff, R. Arevalo Jr., C. Freissinet, S. Getty, D.P. Glavin, S. Siljeström, A. Buch, F. Stalport, A. Grubisic, X. Li, V. Pinnick, R. Danell, F.H.W. van Amerom, F. Goesmann, H. Steininger, N. Grand, F. Raulin, C. Szopa, U.J. Meierhenrich, J.R. Brucato, the MOMA Science Team, MOMA: the challenge to search for organics and biosignatures on Mars, Int. J. Astrobiol. 15 (2016) 239-250.

[204] F. Goesmann, W.B. Brinckerhoff, F. Raulin, W. Goetz, R.M. Danell, S.A. Getty, S. Siljeström, H. Mißbach, H. Steininger, R.D. Arevalo Jr., A. Buch, C. Freissinet, A. Grubisic, U.J. Meierhenrich, V.T. Pinnick, F. Stalport, C. Szopa, J.L. Vago, R. Lindner, M.D. Schulte, J.R. Brucato, D.P. Glavin, N. Grand, X. Li, F.H.W. van Amerom, the MOMA Science Team, The Mars Organic Molecule Analyzer (MOMA) instrument: Characterization of organic material in Martian sediments, Astrobiol. 17 (2017) 655-685. [205] J.P. Grotzinger, J. Crisp, A.R. Vasavada, R.C. Anderson, C.J. Baker, R. Barry, D.F. Blake, P. Conrad, K.S. Edgett, B. Ferdowski, R. Gellert, J.B. Gilbert, M. Golombek, J. Gómez-Elvira, D.M. Hassler, L. Jandura, M. Litvak, P. Mahaffy, J. Maki, M. Meyer, M.C. Malin, I. Mitrofanov, J.J. Simmonds, D. Vaniman, R.V. Welch, R.C. Wiens, Mars Science Laboratory Mission and science investigation, Space Sci. Rev. 170 (2012) 5-56. 
[206] P.G. Conrad, J.L. Eigenbrode, M.O. Von der Heydt, C.T. Mogensen, J. Canham, D.N.

1515 Harpold, J. Johnson, T. Errigo, D.P. Glavin, P.R. Mahaffy, The Mars Science Laboratory Organic Check Material, Space Sci. Rev. 170 (2012) 479-501.

[207] L.A. Leshin, P.R. Mahaffy, C.R. Webster, M. Cabane, P. Coll, P.G. Conrad, P.D. Archer Jr., S.K. Atreya, A.E. Brunner, A. Buch, J.L. Eigenbrode, G.J. Flesch, H.B. Franz, C. Freissinet, D.P. Glavin, A.C. McAdam, K.E. Miller, D.W. Ming, R.V. Morris, R.

1520 Navarro-González, P.B. Niles, T. Owen, R.O. Pepin, S. Squyres, A. Steele, J.C. Stern, R.E. Summons, D.Y. Sumner, B. Sutter, C. Szopa, S. Teinturier, M.G. Trainer, J.J. Wray, J.P. Grotzinger, MSL Science Team, Volatile, isotope, and organic analysis of Martian fines with the Mars Curiosity Rover, Science 341 (2013) 1238937.

[208] C. Meinert, P. de Marcellus, L. Le Sergeant d'Hendecourt, L. Nahon, N.C. Jones, S.V. Hoffmann, J.H. Bredehöft, U.J. Meierhenrich, Photochirogenesis: Photochemical models on the absolute asymmetric formation of amino acids in interstellar space, Phys. Life Rev. 8 (2011) 307-330. 
Fig. 1

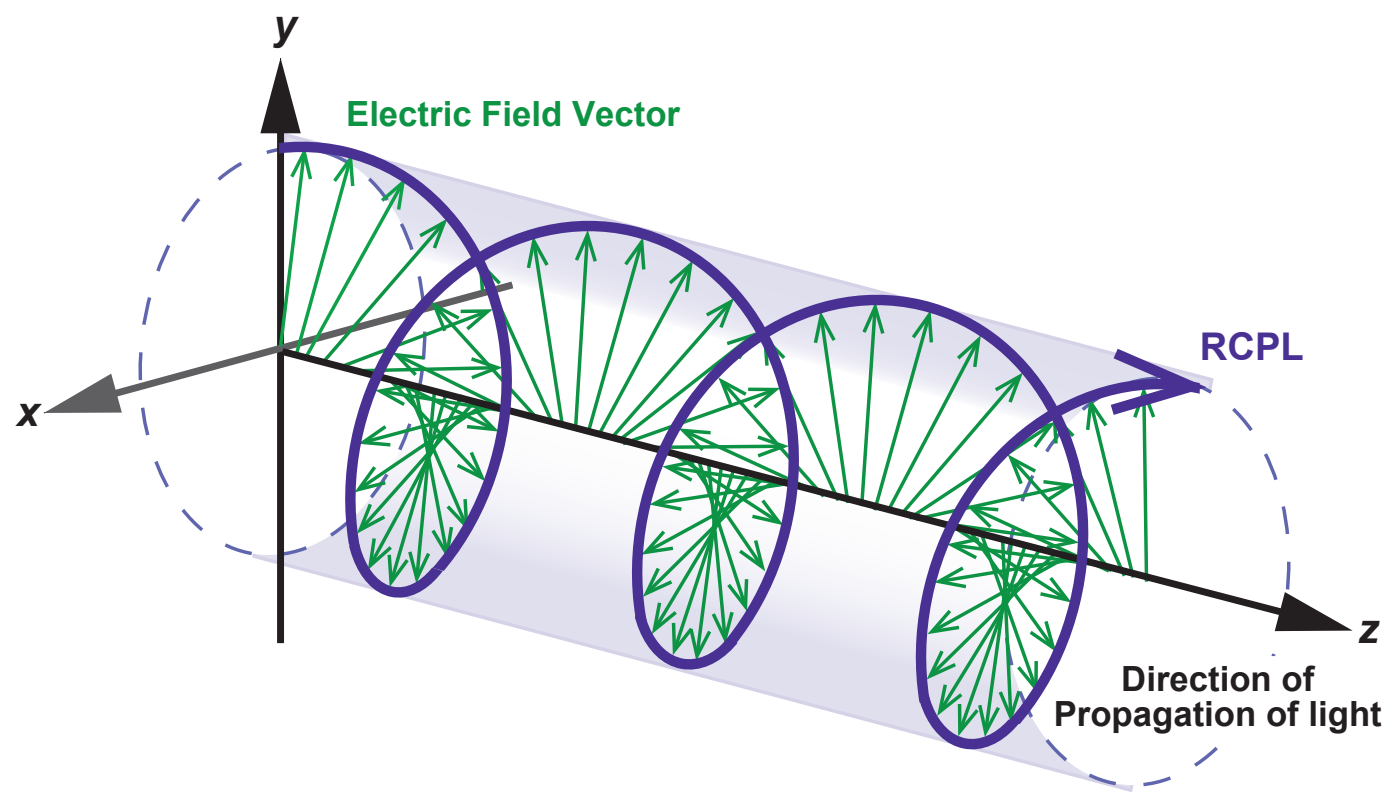


Fig. 2
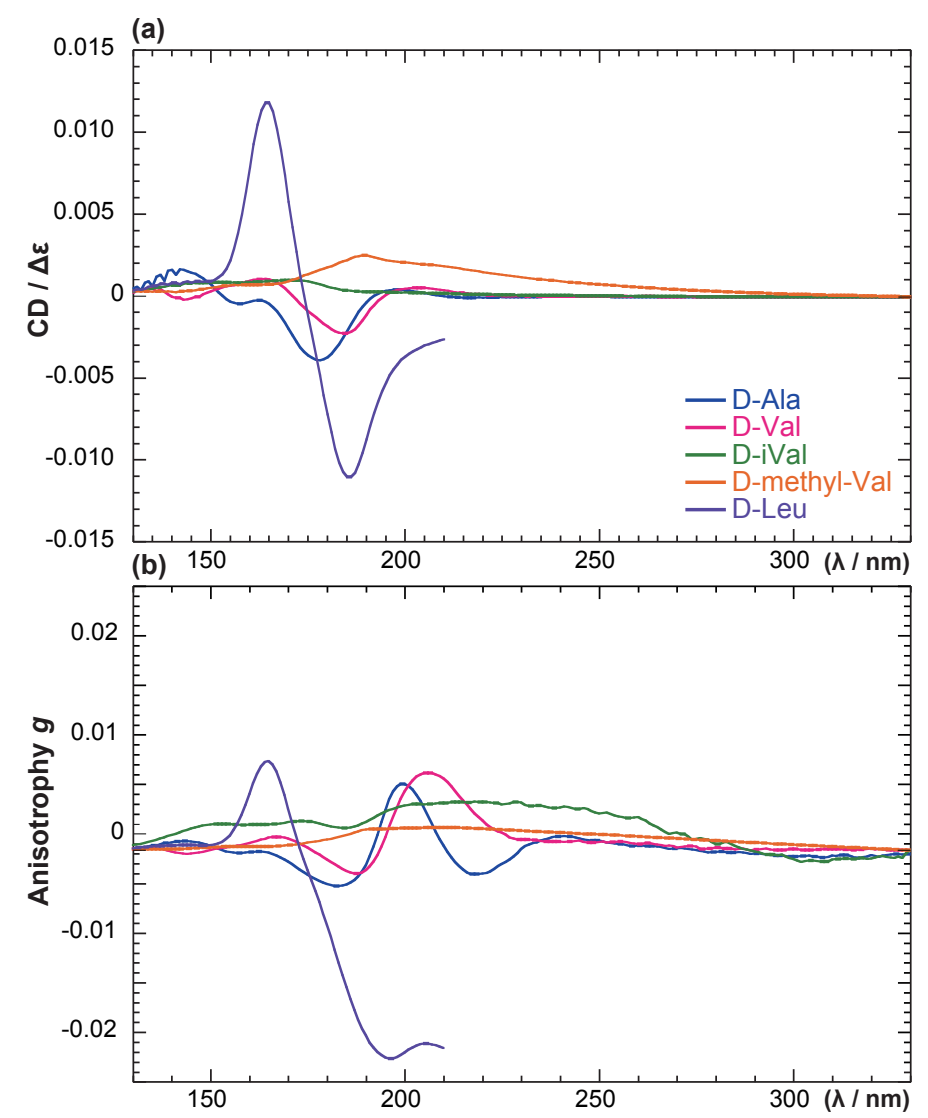
Fig. 3

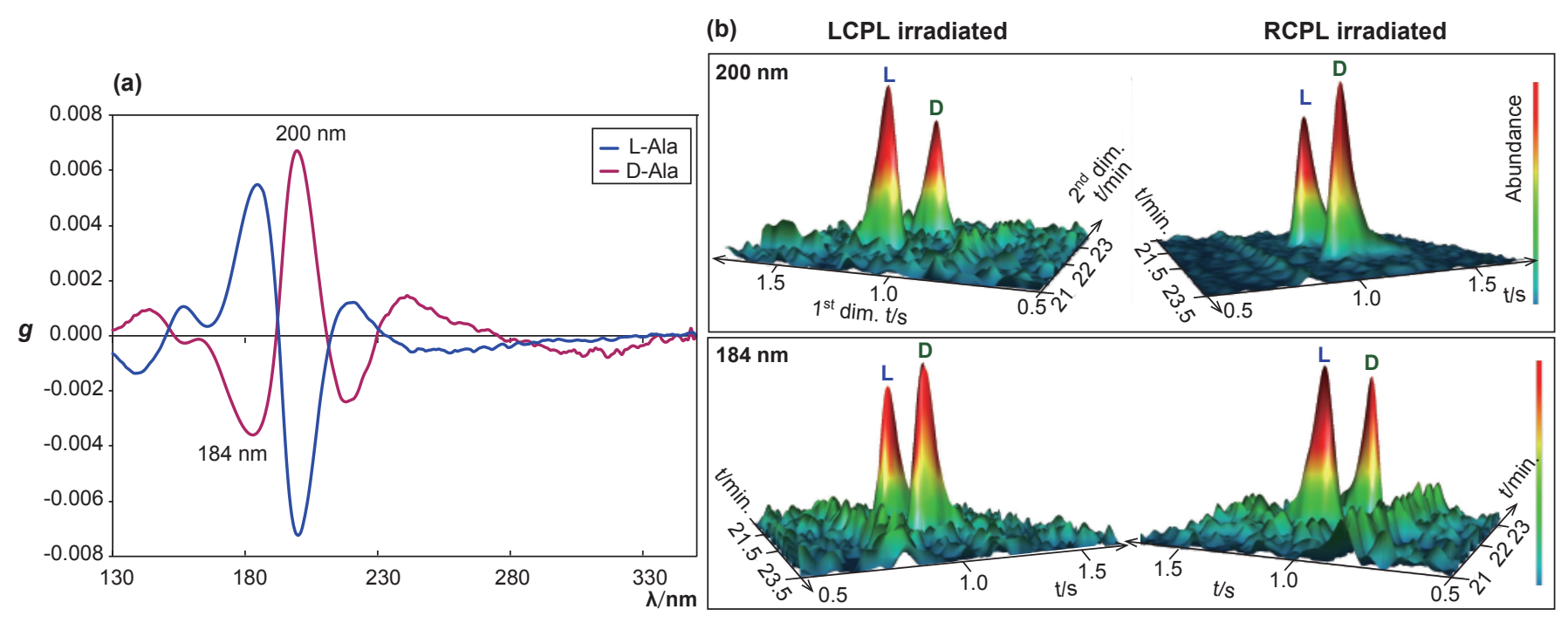


Fig. 4

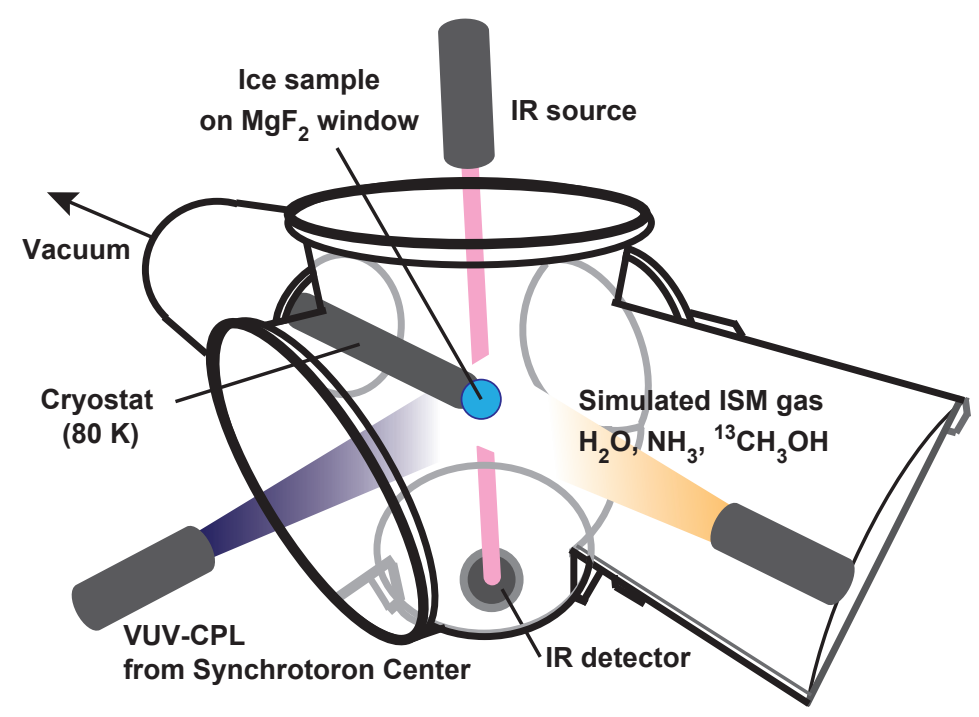


Fig.5

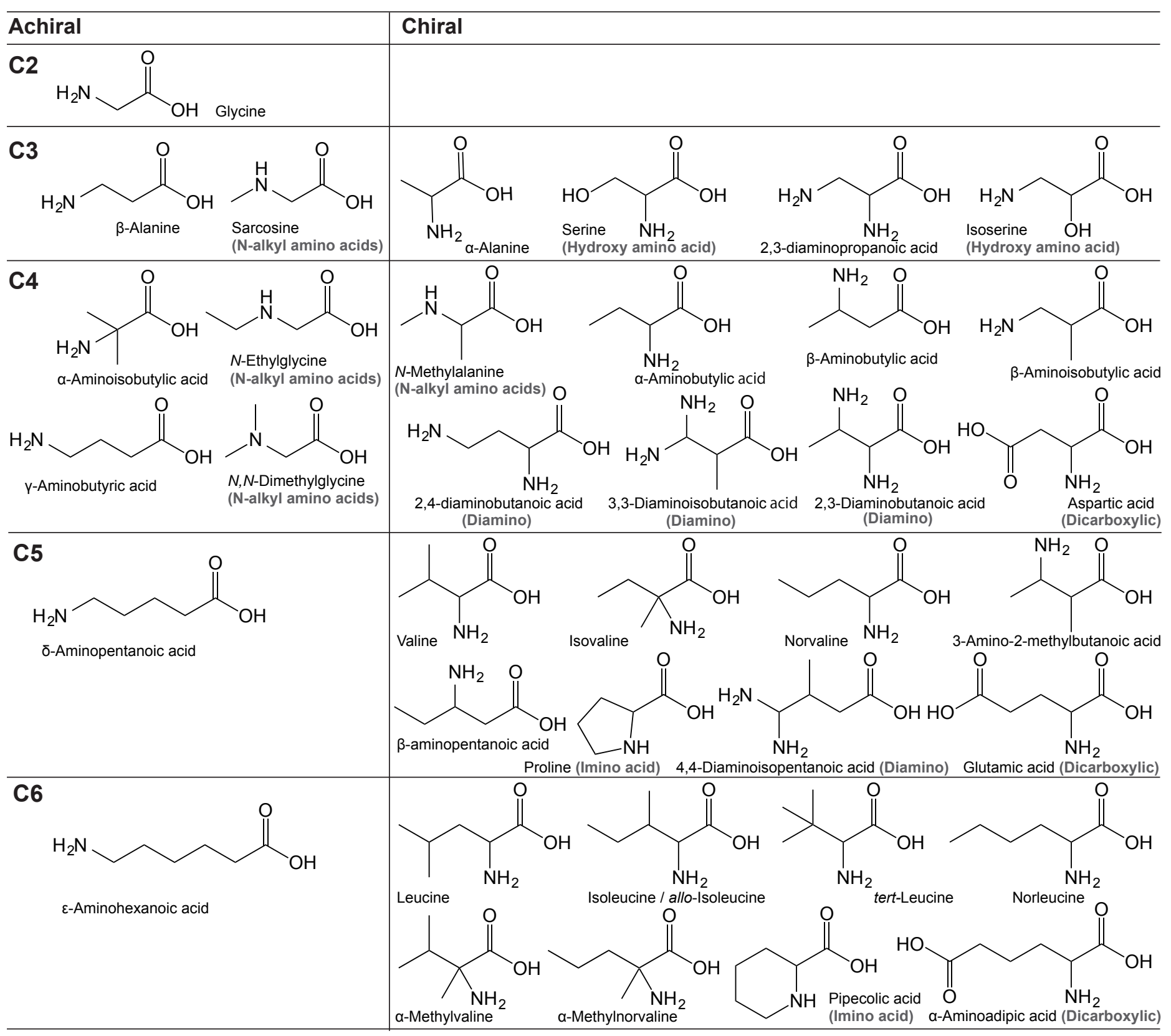


Fig.6

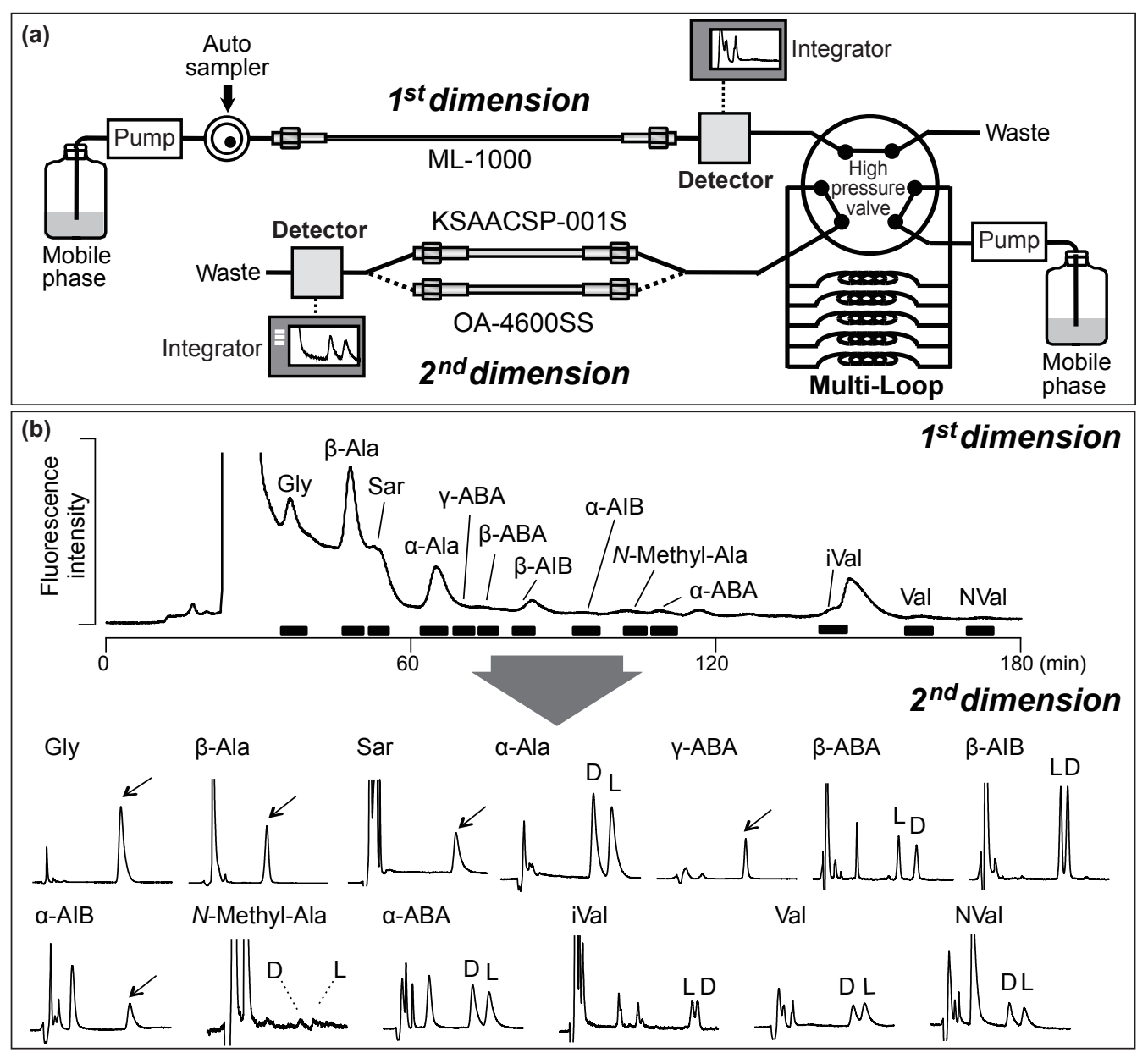


Fig. 7

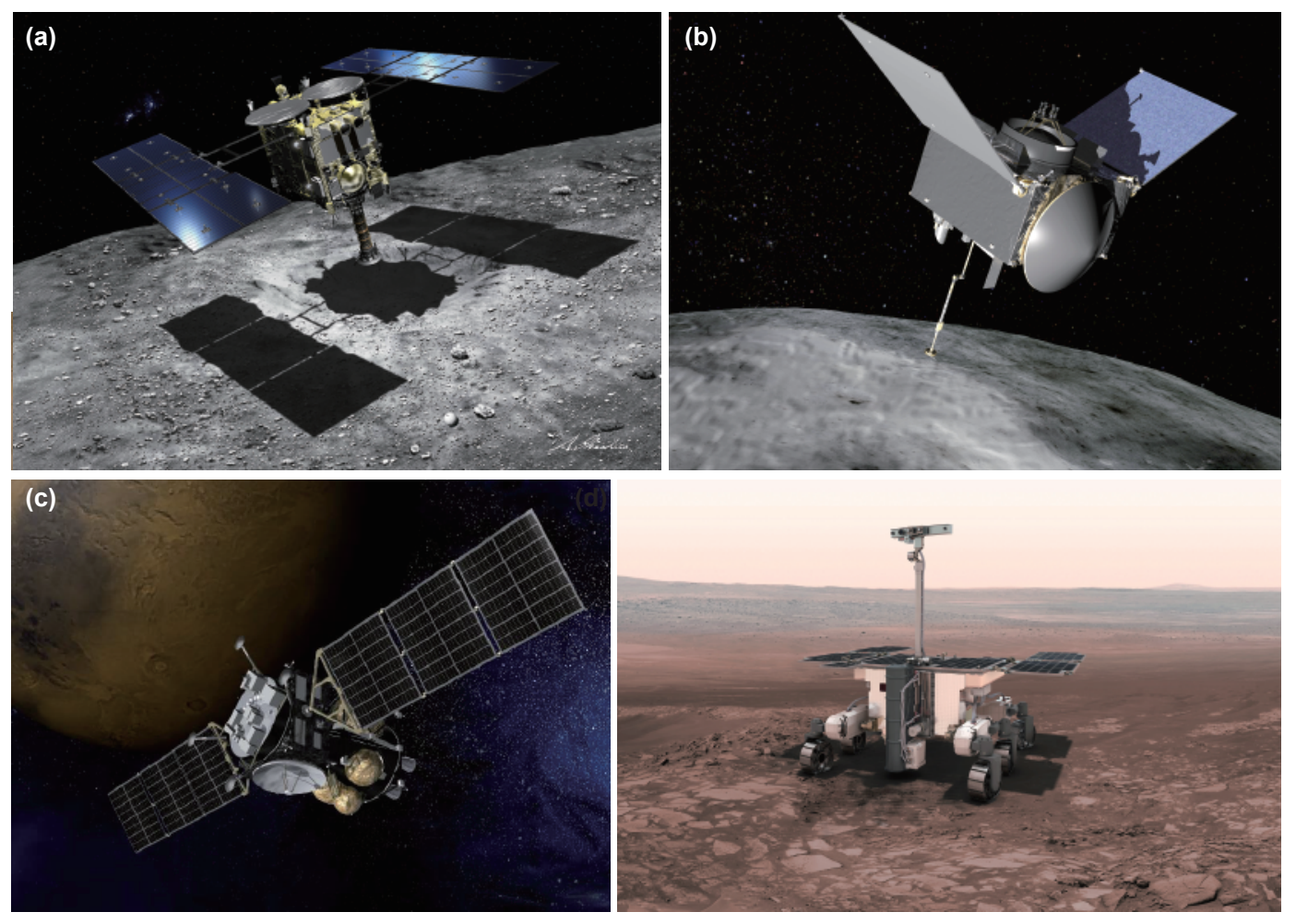

